\title{
Type IV secretion in Gram-negative and Gram-positive bacteria
}

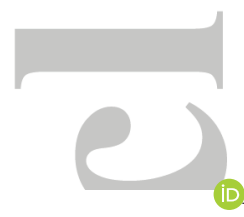

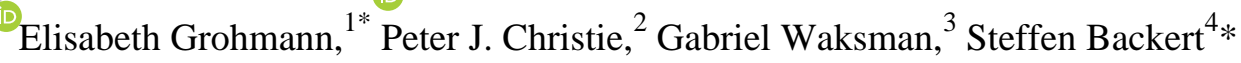

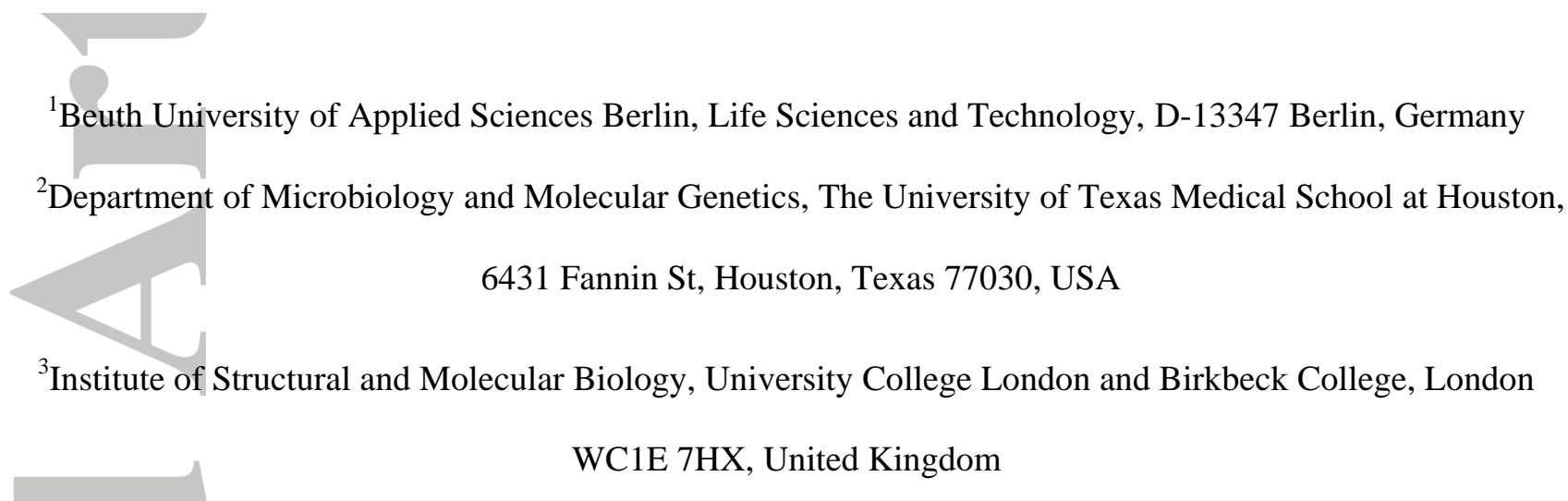

${ }^{4}$ Friedrich Alexander University Erlangen-Nuremberg, Department of Biology, Division of Microbiology, Staudtstrasse 5, D-91058 Erlangen, Germany

*Corresponding authors: elisabeth.grohmann@beuth-hochschule.de and steffen.backert@fau.de

Key words: type IV secretion, T4SS, VirB/VirD4, coupling protein, T4CP, ATPase, NTPase, core structure, conjugation, pilus, mating pair formation, oriT, relaxase, relaxosome, transfer genes, transfer DNA, T-DNA, 3D-structure, CagA, Dot/Icm, vacuole, intracellular trafficking, anti-apoptosis, apoptosis, killer toxin, integrin, CEACAM, signaling, signal transduction

This article has been accepted for publication and undergone full peer review but has not been through the copyediting, typesetting, pagination and proofreading process which may lead to differences between this version and the Version of Record. Please cite this article as an 'Accepted Article', doi: 10.1111/mmi.13896

This article is protected by copyright. All rights reserved. 


\section{Abstract}

Type IV secretion systems (T4SSs) are versatile multiprotein nanomachines spanning the entire bacterial cell envelope in Gram-negative and Gram-positive bacteria. They play important roles through the contactdependent secretion of effector molecules into eukaryotic hosts and conjugative transfer of mobile DNA elements as well as contact-independent exchange of DNA with the extracellular milieu. In the last few years, many details on the molecular mechanisms of T4SSs have been elucidated. Exciting structures of T4SS complexes from Escherichia coli plasmids R388 and pKM101, Helicobacter pylori and Legionella pneumophila have been solved. The structure of the F-pilus was also reported and surprisingly revealed a filament composed of pilin subunits in 1:1 stoichiometry with phospholipid molecules. Many new T4SSs have been identified and characterized, underscoring the structural and functional diversity of this secretion superfamily. Complex regulatory circuits also have been shown to control T4SS machine production in response to host cell physiological status or a quorum of bacterial recipient cells in the vicinity. Here, we summarize recent advances in our knowledge of 'paradigmatic' and emerging systems, and further explore how new basic insights are aiding in the design of strategies aimed at suppressing T4SS functions in bacterial infections and spread of antimicrobial resistances.

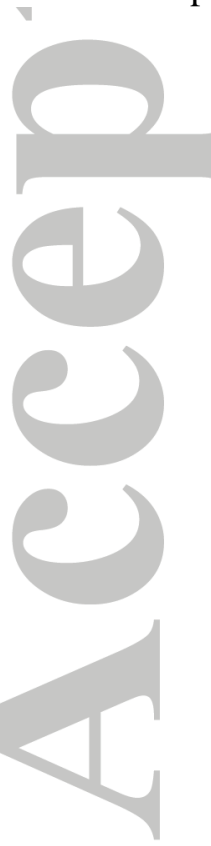




\section{Introduction}

The T4SSs represent a highly diverse superfamily of secretion systems found in many bacterial species. This diversity is represented at a functional level by an astounding collective capacity of T4SSs to i) recognize and translocate single-stranded (ss) DNA substrates (conjugation machines) to bacterial recipients, ii) deliver effector proteins (effector translocator systems) to eukaryotic target cells, iii) exchange DNA with the milieu, iv) contribute to biofilm development, and v) deliver a killing toxin to bacterial neighbors (Figs. 1A-D). Many pathogenic bacteria deploy T4SSs as virulence determinants aiding their colonization and propagation in the eukaryotic host (Fig. 1E). Most if not all T4SS-carrying species alternatively utilize these machines to disseminate mobile genetic elements, often rife with antibiotic resistance genes and other fitness traits, for enhanced survival in clinical and other environmental settings. In this MicroReview, we summarize intriguing advances in studies of the evolution, structure, and function of T4SSs operating in various human pathogens. Our new insights form an important foundation for emerging translational studies aimed at suppressing the action of T4SSs in pathogenic bacteria or repurposing T4SSs for therapeutic ends.

\section{Evolution of the structurally and functionally diverse T4SS superfamily}

The T4SSs can be viewed as composite structures of two or more functional protein modules. The large subfamily of conjugation systems in Gram-negative $\left(\mathrm{Gram}^{-}\right)$bacteria is composed of four such units: i) the relaxosome responsible for nicking DNA substrates at their origin of transfer (oriT) sequences, ii) the type IV coupling protein (T4CP) functioning as a substrate receptor, iii) the cell-envelope-spanning T4SS machine constituting the mating channel, and iv) an extracellular pilus important for establishment of intercellular contacts and robust biofilm development (Alvarez-Martinez and Christie, 2009; Christie, 2016). Over the last few years, phylogenetic studies have focused on delineating the ancestral relationships of several key components of these functional modules. For example, the relaxase enzymes in the relaxosome likely evolved from rolling circle replicases (Garcillan-Barcia et al., 2009), whereas T4CPs and the VirB4 ATPase components of the T4SS channel evolved from ancestral SpoIIIE/FtsK-like ATPases (Guglielmini et al., 2013; 2014). Mating channels likely functioned originally as protein transport systems and evolved as 
conjugation systems through recognition by T4CPs of rolling circle replicases as substrates. By tracing the evolutionary paths of the signature T4CP and VirB4 ATPases, the conjugation systems are thought to have emerged first in the diderm $\left(\mathrm{Gram}^{-}\right)$species and then expanded to the monoderm Gram-positive $\left(\mathrm{Gram}^{+}\right)$ species. These systems then diverged on a relatively recent evolutionary time scale to generate the extreme biological diversity of the T4SSs ranging from the widely distributed conjugation machines to dedicated effector translocator systems to various other systems adapted for entirely novel purposes (Bhatty et al., 2013; Guglielmini et al., 2013; 2014).

The T4SSs of Gram bacteria have been classified into two broad phylogenetic subfamilies, designated as types IVA and IVB. The Agrobacterium tumefaciens VirB/VirD4 T4SS and E. coli conjugation apparatuses, encoded by the R388 and pKM101 plasmids, have served as paradigms of the type IVA systems (Chandran Darbari and Waksman, 2015; Christie, 2016). These T4SSs characteristically are composed of 12 subunits, each in multiple copies, termed VirB1 through VirB11 and VirD4 based on the $A$. tumefaciens subunit names as a unifying nomenclature for this secretion superfamily. Of these, VirB2VirB11 and VirD4 are required for substrate transfer, whereas VirB1 is necessary and VirD4 is dispensable for assembly of the conjugative pilus. The subunits can be grouped according to general function or subcellular location as: i) the cytoplasmic ATPases (VirB4, VirB11, VirD4), ii) components of an inner membrane platform (VirB3, VirB6, VirB8), iii) constituents of an outer membrane core complex (OMCC; VirB7, VirB9, VirB10), and iv) pilus-assembly components (VirB1 transglycosylase, VirB2 pilin, VirB5 pilus-tip protein). As described in more detail below, recent structure - function studies are advancing our mechanistic knowledge of these 'paradigmatic' systems. Two other well-characterized systems, the T4SS encoded by E. coli F plasmids and the Cag (Cytotoxin-associated genes) T4SS encoded by H. pylori, are composed of orthologs by all the VirB/VirD4 proteins, and thus are classified as type IVA. However, these systems additionally require many F- and Cag-specific subunits for their assembly, and thus likely have novel structural and functional features (Backert et al., 2015; Christie, 2016). The type IVB transporters also require many (>25) proteins for their assembly, of which only a few are related to the VirB/VirD4 subunits and over 20 are specific for the IVB machineries. The L. pneumophila Dot/Icm (Defective for organelle 
trafficking/Intracellular multiplication) system serves as a paradigm for this subfamily (Nagai and Kubori, 2011).

The T4SSs have evolved as highly-specialized nanomachines both in recognition of specific substrate repertoires and in delivery of substrates to specific prokaryotic or eukaryotic cell types. This specialization arose largely through appropriation by the ancestral conjugation systems of novel motifs, proteins or protein subassemblies (Christie, 2016). For example, there is accumulating evidence that many VirD4 substrate receptors have acquired sequence-variable C-terminal extensions (CTEs) that are capable of binding secretion chaperones or adaptors, often required for secretion of associated substrates. These VirD4 CTE - adaptor interactions play important roles in defining the substrate repertoire of cognate T4SSs. Additionally, the VirB6 subunits typically consist of five or more inner membrane-spanning helices, but a large subfamily of these subunits (called extended VirB6's) have acquired large hydrophilic domains shown to extend to the cell surface or into target cells to modulate the bacterial donor-target cell interaction. Similarly, the VirB7 and VirB10 subunits typically form part of the OMCC, yet variants of these subunits carry long variable repeat sequences implicated in specifying host cell recognition or immune evasion (Christie, 2016). Recent genomics studies also have identified redundant but sequence-variable copies of genes encoding VirB2 and VirB5 pilin subunits; these pilins also are thought to assemble as surface-variable structures enabling modulation of host cell binding or persistence in an infection setting (Alvarez-Martinez and Christie, 2009; Gillespie et al., 2009; 2010; Vayssier-Taussat et al., 2010). Finally, there also is increasing evidence that T4SSs have appropriated other bacterial host proteins, e.g., surface-exposed adhesins or outer membrane proteins (OMPs), to promote binding to other bacterial or eukaryotic cell targets as a prerequisite for interbacterial gene or interkingdom effector protein transfer (Bhatty et al., 2015; Javaheri et al., 2016; Königer et al., 2016). This structural and functional diversity is especially evident among the T4SSs deployed by important human pathogens for effector translocation, as highlighted later in this MicroReview. 


\section{T4SS architecture and pilus formation}

Over the last decade, there has been significant progress in deciphering the structures of T4SS subassemblies from conjugation machines functioning in E. coli and from T-DNA transfer in A. tumefaciens. These structures represent an architectural blueprint for the IVA transporters that, coupled with results of earlier formaldehyde crosslinking studies in the A. tumefaciens VirB/VirD4 system (Atmakuri et al., 2004; Cascales and Christie, 2004), generate a view of how secretion substrates are conveyed through the T4SS to the cell surface. Until now the structures of three T4SSs have been reported, two of isolated machines and one in the native context of the bacterial cell envelope. The best-characterized structures to date have been presented for the Trw T4SS encoded by plasmid R388, achieved by negative-stain and cryo-electron microscopy (cryoEM) imaging of isolated machines. The largest structure is designated the $\mathrm{VirB}_{3-10}$ assembly because it is composed of homologs of the A. tumefaciens VirB3-VirB10 subunits (Low et al., 2014). This 3 MegaDalton complex consists of a large outer membrane subassembly called the core complex (Fig. 1F). Core complex structures also have been presented for the plasmid pKM101-encoded T4SS at a high resolution and for the A. tumefaciens VirB/VirD4 T4SS at a lower resolution (Chandran et al., 2009; Fronzes et al., 2009; Rivera-Calzada et al., 2013; Gordon et al., 2017). The R388 VirB $3-10$ structure is additionally composed of an inner membrane complex (IMC) of extraordinary design and a slight flexible section (the stalk), connecting the core complex with the IMC (Trokter et al., 2014). The IMC is composed of 12 copies each of VirB3, VirB4, VirB5, VirB6, and VirB8, coming together to form a double-barreled structure, each of the barrels protruding in the cytoplasm. These barrel-shaped structures are each made of the VirB4 ATPase, observed here as trimers of VirB4 dimers. Cryo-EM of the pKM101 core complex identified a ring structure of $185 \AA$ in diameter, comprising the VirB7, VirB9 and VirB10 proteins (Fig. 1G, top), each existent in 14 copies (Fronzes et al., 2009; Rivera-Calzada et al., 2013). In fact, this complex is composed of inner (I) and outer (O) layers. The O-layer is formed by VirB7 and the C-terminal domains of VirB9 and VirB10. The $2.6 \AA$ resolution O-layer structure revealed that VirB10 forms the interior lining of the complex while VirB9/VirB7 forms a protective crown around it. Fourteen VirB10 subunits project each a helical bundle to form a highly unusual outer-membrane channel (Chandran et al., 2009). The cryo-EM assembly of 
a truncated pKM101 core structure, lacking the N-terminus of VirB10 (Fig. 1G, bottom), was determined at 8.5 $\AA$ resolution and provided further details on the structure of the I-layer (Rivera-Calzada et al., 2013). The I-layer in the arrangement is composed of 14 VirB9 N-terminal domains and covers the outer wall. Molecular modeling supported the view that these domains represent $\beta$-sandwich folds. Remarkable projections from a middle platform tighten the channel, connecting the chambers in the O-layer and I-layer (Fig. 1G, bottom right). This podium is apparently formed by VirB9, with proposed function in effector molecule delivery across the core complex. In addition, three NTPases (VirB4, VirB11 and VirD4) function as hexamers (Yeo et al., 2000; Gomis-Rüth et al., 2001; Savvides et al., 2003; Hare et al., 2006; Wallden et al., 2012). They face the cytoplasm and are essential for substrate secretion. Two of these NTPases (VirB4 and VirB11) are also essential for extracellular pilus formation. T4SS-pili represent tube-like appendages (Eisenbrandt et al., 1999; Wang et al., 2009), and stimulate contact and subsequent mating pair formation with the recipient (Dürrenberger et al., 1991; Samuels et al., 2000; Hospenthal et al., 2017). However, the composition of these mating bridges is not fully explored. It appears that conjugative pili function as conduits for DNA transfer and can appear at significant cell-to-cell distances (Babic et al., 2008). Interestingly, uncoupling mutations in agrobacterial T4SS proteins blocked pilus biogenesis, but allowed proper DNA transfer (Jakubowski et al., 2009; Banta et al., 2011). This implied that intact pili are not necessary for substrate transfer. However, production of VirB2 and VirB5 is important for proper T4SS function and host cell interaction (Berger and Christie, 1993; Backert et al., 2008). These data together denote the existence of two configurations for the IVA-type T4SSs, a pilus biogenesis-competent form and a secretion-competent form, that may be composed of a pilus structure extending through the chamber of the OMCC (Banta et al., 2011).

Several other T4SS-associated structures have been solved, including a recent cryo-EM structure of a relaxase that revealed the molecular basis of DNA unwinding during bacterial conjugation (Fig. 1H-J) (Ilangovan et al., 2017). A structure of a VirD4 coupling protein bound to a VirB-type T4SS machinery was also described, providing a view of how secretion substrates might be conveyed through the T4SS (Fig. 1J) (Redzej et al., 2017). Structures of the H. pylori Cag (Frick-Cheng et al., 2016) and $L$. 
pneumophila Dot/Icm systems (Ghosal et al., 2017) have been reported, although not yet at the resolution of the R388 VirB $3-10$ structure. Even at this time, however, these structures allow for general comparisons between the 'paradigmatic' VirB/VirD4-like type IVA machines and phylogenetically diverse systems; for example, the IVA and IVB types have a similar architecture consisting of a 14-fold symmetrical core complex mounted through a stalk to a double-barreled IMC. Finally, in addition to the structures solved for plasmid-encoded T4SSs or subassemblies, in the last year atomic models were solved by cryo-EM for two $\mathrm{F}$ family pili. Strikingly, these pili are composed of TraA pilin subunits in 1:1 stoichiometric association with phospholipid (Costa et al., 2016). These structures provide a molecular basis for understanding the dynamics of F-pilus assembly and retraction (Costa et al., 2016). Taken together, these new T4SS structures represent significant breakthroughs in the field of bacterial secretion.

\section{Nature and recruitment of T4SS substrates}

Pioneering work on the nature and recruitment of T4SS substrates, with focus on conjugative plasmids from Gram bacteria, has been performed by the groups of Llosa and Zechner (Fernandéz-Gonzaléz et al., 2011; Zechner et al., 2012; Lang et al., 2014; Gruber et al., 2016). All conjugative T4SSs encode relaxases, which initiate substrate processing by a nucleophilic attack of the active site tyrosyl-hydroxyl group of the enzyme on the scissile phosphate group within oriT, releasing the bridging oxygen and forming a long-lived ssDNAprotein conjugate. This high-energy bond serves several functions: i) it physically links the ssDNA substrate with the relaxase whose translocation signal (TS) mediates transfer through the T4SS, ii) it protects the phosphate of the ssDNA from nucleophilic attack when it enters the recipient, and iii) it provides the means to rejoin the plasmid ends in the recipient (Zechner et al., 2012). T4SS substrates are equipped with TSs that identify them as substrates for secretion (Zechner et al., 2012). Redzej and co-workers reported the first structure of a TS in relaxase TraI from plasmid R1 (Redzej et al., 2013). The latter TS domain can be divided into three subdomains with striking structural homology to helicase subdomains of the SF1B family. This work provided the first evidence that the TS can be part of larger structural scaffolds, overlapping with translocation-independent activities (Redzej et al., 2013). 
Before entering the secretion channel, T4SS substrates form complexes with specific cytosolic binding partners, which can act as chaperones or adaptors to mediate substrate contacts with the cognate T4CP (Zechner et al., 2012). In the F system, for example, the TraM accessory factor functions in substrate selection by promoting a specific interaction between the F plasmid substrate and the F-encoded TraD T4CP (Wong et al., 2012). Other characterized T4SS accessory factors include the VirE1 chaperone, required for translocation of the VirE2 effector through the A. tumefaciens VirB/VirD4 T4SS, and the IcmS, IcmW, LvgA adaptors essential for translocation of different subsets of effectors through the Legionella Dot/Icm translocation apparatus (Alvarez-Martinez and Christie, 2009; Kwak et al., 2017). Par-like proteins such as A. tumefaciens VirC1 and VirC2 (Atmakuri et al., 2007) and R1 plasmid-encoded ParM and ParR (Gruber et al., 2016) also appear to play a role in promoting the docking of the T-DNA and R1 DNA substrates with their cognate T4SSs.

In $\mathrm{Gram}^{+}$bacteria, the DNA processing steps prior to conjugative transfer appear to be mechanistically very similar (Zechner et al., 2012). One exception to this generalization is that the Clostridium perfringens plasmid pCW3 codes for an atypical relaxase in the sense that it carries a catalytic tyrosine residue. Other catalytic residues conserved in tyrosine recombinases are not required for TcpM activity, suggesting that TсрM is not a site-specific recombinase (Wisniewski et al., 2016). Also, the first evidence was presented that a T4SS deployed by a $\mathrm{Gram}^{+}$species functions to deliver effector proteins to eukaryotic host cells during the course of infection (Li et al., 2011; Zhao et al., 2011; Jiang et al., 2016; Yin et al., 2016). This T4SS is encoded by the $89 \mathrm{~kb}$ pathogenicity island (called $89 \mathrm{~K}$ PAI) associated with Streptococcus suis and is also found in other pathogenic streptococci, e.g., S. pneumoniae, S. agalactiae (Wang et al., 2017). It will now be of considerable interest to confirm effector translocation, identify the effector repertoire, and define the nature of the translocation signals required for translocation through this and other possible effector translocators in $\mathrm{Gram}^{+}$species.

\section{Conjugative transfer systems}

Conjugative T4SSs are encoded on conjugative plasmids, integrative and conjugative elements also known as ICEs or conjugative transposons, or genomic PAIs (Fig. 1A). These systems are found in most species of 
$\mathrm{Gram}^{-}$and $\mathrm{Gram}^{+}$bacteria, and conjugative plasmids also exist in a few species of archaea (Wagner et al., 2017). In bacteria, these mobile genetic elements contribute to the spread of fitness traits and, more problematically from a clinical perspective, multiple antibiotic resistances (Christie, 2016; Grohmann et al., 2016). As mentioned earlier, the prototypic systems among $\mathrm{Gram}^{-}$species include the A. tumefaciens VirB/VirD4 T4SS (Christie, 2016), and the E. coli conjugative plasmids F, R388, and pKM101 (Lawley et al., 2003; Llosa and de la Cruz, 2005; de la Cruz et al., 2010; Frost and Koraimann, 2010; Zechner et al., 2012, Arutyunov and Frost, 2013; Koraimann and Wagner, 2014; Cabezon et al., 2015).

Currently, the best characterized T4SSs from $\mathrm{Gram}^{+}$bacteria are those encoded by the Enterococcus faecalis sex-pheromone responsive plasmid pCF10 (Li et al., 2012; Clewell et al., 2014; Laverde Gomez et al.; 2014; Bhatty et al., 2015; Whitaker et al., 2015; Bhatty et al., 2017), C. perfringens plasmid pCW3 (Bantwal et al., 2012; Porter et al., 2012; Wisniewski et al., 2015; 2016; Wisniewski and Rood, 2017) and broad-host-range plasmid pIP501 originally isolated from S. agalactiae (Arends et al., 2013; Goessweiner-Mohr et al., 2013 a and b; 2014 a and b; Fercher et al., 2016; Grohmann et al., 2016; Kohler et al., 2017; Laverde et al., 2017). The conjugation machines in $\mathrm{Gram}^{+}$species differ from their Gram species counterparts mainly by lacking the outer membrane core complex and the VirB11 ATPase. They also do not produce conjugative pili and instead rely on surface adhesins to mediate donor-recipient cell contacts (Bhatty et al., 2013; 2015). The $\mathrm{Gram}^{+}$systems also typically employ VirB1-like lytic transglycosylases with two or more catalytic domains, presumably to allow for machine assembly across the thick peptidoglycan layer (Arends et al., 2013; Laverde Gomez et al., 2014).

With respect to structure - function advances of the $\mathrm{Gram}^{+} \mathrm{T} 4 \mathrm{SSs}$, high-resolution structures of individual components from the pIP501 and pCW3 systems have been solved (Porter et al., 2012; Goessweiner-Mohr et al., 2013a; 2014b; Fercher et al., 2016), although no structures are presently available for larger T4SS machine assemblies. Considerable progress also has been made in defining signaling cascades and regulatory networks governing assembly of several $\mathrm{Gram}^{+}$systems. In the E. faecalis T4SS, pheromone-dependent overproduction of $\operatorname{PrgB}$, otherwise known as Aggregation Substance, induces formation of intercellular aggregates. Interestingly, however, upon overproduction, $\operatorname{PrgB}$ confers toxicity on 
E. faecalis donors by a mechanism dependent on extracellular DNA (e-DNA) (Bhatty et al., 2015). A gene linked to $\operatorname{prgB}$ codes for a putative RNA-binding protein termed $\operatorname{Prg} \mathrm{U}$, whose synthesis mitigates $\operatorname{PrgB}$ overproduction toxicity by blocking transcription from the upstream $\operatorname{prg} Q$ promoter (Bhatty et al., 2017). Studies also have deciphered regulatory features and the molecular organization of the ICEBs 1 -encoded T4SS carried by Bacillus subtilis (Carraro and Burrus, 2014; DeWitt and Grossman, 2014; Johnson and Grossman, 2015; Leonetti et al., 2015; Auchtung et al., 2016). Finally, as noted above, the intriguing recent studies of the $89 \mathrm{~K}$ PAI from $S$. suis for the first time have supplied evidence that a T4SS encoded by a Gram ${ }^{+}$ species is capable of translocating effector proteins into human host cells during the course of infection (Li $e t$ al., 2011; Jiang et al., 2016; Yin et al., 2016).

\section{DNA export and import systems}

The subfamily of contact-independent import/export machines is presently restricted to the $H$. pylori ComB competence system and the Neisseria gonorrhoeae DNA release apparatus (Figs. 1B,C). In the ComB system, the T4SS mediates the first step in DNA uptake across the outer membrane (Hofreuter et al., 1998; 2000; Stingl et al., 2010, Krüger and Stingl, 2011). This apparatus was identified as the major mediator of DNA transfer between $H$. pylori strains, both in a DNaseI-sensitive (transformation) and DNaseI-resistant (conjugative transfer) manner (Rohrer et al., 2012). The ComB system comprises a nearly complete set of T4SS components, lacking only the homologs of VirB1, VirB5, and VirB11 ATPase (Fernández-González and Backert, 2014). An early study showed that all VirB homologs except for the VirB7-like subunit are required for DNA uptake (Hofreuter et al., 2003). In addition to the ComB subunits, the cytoplasmic protein DprA (Smeets et al., 2000a), the secreted protein ComH (Smeets et al., 2000b), and the cytoplasmic channel subunit ComEC (Yeh et al., 2003) are essential for DNA import by H. pylori (Fernández-González and Backert, 2014). Recently, a two-step DNA uptake mechanism was proposed in which ComB translocates double-stranded (ds) DNA across the outer membrane and delivers the substrate to the ComEC channel for uptake across the inner membrane (Stingl et al., 2010; Fernández-González and Backert, 2014). It also has 
been suggested that some $\operatorname{comB}$ genes might contribute to $H$. pylori infection of mammalian host cells (Fernández-González and Backert, 2014).

Neisseria gonorrhoeae is an obligate human pathogen responsible for the sexually transmitted disease gonorrhea. It encodes a plasmid F-like T4SS within the gonococcal genetic island (GGI), which secretes ssDNA directly into the external environment (Pachulec et al., 2014). This DNA is effective in transforming gonococci in the population, and may contribute to the high extent of genetic diversity in this species (Kohler et al., 2013). Secretion of ssDNA is also required for the initial stages of biofilm formation, presumably helping during colonization (Zweig et al., 2013; Obergfell and Seifert, 2015) (Fig. 1B). Sequence comparisons revealed that GGI-like T4SSs are highly conserved units located both on chromosomes and plasmids. The yaa-atlA and parA-parB gene regions were shown to be essential for DNA secretion (Pachulec et al., 2014). In addition, it was postulated that release of DNA occurs through the action of ParA, ParB, TraI, Yea, and TraD proteins. Reminiscent of the VirC1/VirC2 and ParM/ParR systems described earlier, the N. gonorrhoeae ParA and ParB are partitioning factors implicated in chromosome and plasmid DNA segregation during replication, but evidently also coordinate early DNA substrate docking reactions with the cognate GGI-encoded T4SSs (Leonard et al., 2005; Obergfell and Seifert, 2015).

\section{Host-pathogen interactions}

\section{Helicobacter pylori}

Helicobacter pylori is a paradigm of persistent pathogens and major risk factor of peptic ulceration and gastric adenocarcinoma in humans (Salama et al., 2013). Highly virulent isolates elaborate a T4SS encoded by the cag PAI. Machine assembly requires orthologs of all 12 agrobacterial VirB/VirD4 proteins and about a dozen other subunits, making this system clearly distinct from the 'paradigmatic' IVA systems discussed above (Fischer et al., 2001; Backert et al., 2015). The T4SS core complex was visualized by negativestaining EM, bearing some architectural similarity to the R388-encoded VirB $\mathrm{B}_{3-10}$ subassembly (Frick-Cheng et al., 2016). However, the Cag structure is considerably larger with a cross-section of $41 \mathrm{~nm}$ as opposed to $28 \mathrm{~nm}$, and it is composed of five (Cag3, CagM, CagT, CagX, CagY) as opposed to three (VirB7, VirB9, 
VirB10) subunits, respectively. The Cag T4SS also was shown to be associated with an extracellular pilus (Backert et al., 2015). Another distinction from the canonical systems is that several subunits, including CagL, CagI, CagY and the CagA secretion substrate, are associated with the surface-exposed portion of the pilus. These factors permit binding of the basolateral host receptor integrin $\alpha_{5} \beta_{1}$, which is necessary for T4SS function (Kwok et al., 2007; Barden et al., 2013). New studies revealed that T4SS-pilus formation occurred predominantly at basolateral membranes during infection of polarized gastric epithelial cells, and not at apical sites. For this purpose, H. pylori secretes the serine protease HtrA, which opens cell-to-cell junctions through cleavage of the junctional proteins occludin, claudin-8 and E-cadherin (Schmidt et al., 2016; Tegtmeyer et al., 2017a). The only known Cag T4SS effector protein is CagA, and several crystal structures of CagA's N-terminus are now available (Hayashi et al., 2012; Kaplan-Türköz et al., 2012). After delivery into host cells, CagA undergoes tyrosine phosphorylation by cellular Src and Abl kinases (Mueller et al., 2012). CagA can then interact with about 25 signaling proteins, including Shp2, Grb2, Par1b, PI3-kinase or tumor suppressor ASPP2 (Higashi et al., 2002; Mimuro et al., 2002; Saadat et al., 2007; Selbach et al., 2009, Nešić et al., 2014; Zhang et al., 2015). Through these interactions, CagA interferes with fundamental host signaling cascades such as cell adhesion, polarity, proliferation, anti-apoptosis and inflammation (Tegtmeyer et al., 2017b). Functional studies in Mongolian gerbils (Franco et al., 2008) and transgenic mice (Ohnishi et al., 2008) have shown that CagA production is necessary and sufficient to stimulate gastric cancerogenesis. However, besides CagA, this T4SS can translocate chromosomal DNA (Varga et al., 2016), peptidoglycan (Viala et al., 2004) and D-glycero- $\beta$-D-manno-heptose 1,7-bisphosphate (Gall et al., 2017; Stein et al., 2017; Zimmermann et al., 2017) into epithelial cells, which respectively stimulate TLR-9, kinase AKAP and proinflammatory transcription factor $\mathrm{NF}-\kappa \mathrm{B}$ signaling modules. H. pylori also exploits host CEACAM (carcinoembryonic antigen-related cell adhesion molecules) receptors via the surface-exposed OMP HopQ, for bacterial adherence and translocation of CagA. The HopQ - CEACAM interaction is necessary for full T4SS function, gastric colonization and pathology (Javaheri et al., 2016; Königer et al., 2016). 


\section{Legionella pneumophila}

Several intracellular pathogens including Legionella, Coxiella, Bartonella and Brucella species produce specialized T4SSs to aid in survival and spread in the human host (Personnic et al., 2016; Sherwood and Roy, 2016). Legionella pneumophila is an environmental amoeba-adapted parasite that also colonizes human alveolar macrophages, hence triggering severe pneumonia, called Legionnaires' disease (Vogel and Isberg, 1999). To evade killing by the host, the L. pneumophila convert phagosomes into a protective compartment termed the "Legionella-containing vacuole" (LCV). Formation of this replicative niche requires the Dot/Icm T4SS. EM studies have visualized the Dot/Icm T4SS core as a ring-shaped structure composed of five proteins, DotC, DotD, DotF, DotG and DotH (Kubori et al., 2014). More recently, the Dot/Icm core complex was visualized by cryo-electron tomography of L. pneumophila cells. This structure more closely resembles the H. pylori Cag T4SS in its size (41 nm cross-section) and overall architecture (Ghosal et al., 2017). However, in contrast to the R388-encoded $\mathrm{VirB}_{3-10}$ structure, which presents information about the IMC, at present there is no knowledge of how the inner membrane subassemblies of either the Dot/Icm or Cag T4SSs are architecturally configured. Interestingly, the Dot/Icm system assembles at Legionella cell poles, and polar translocation of effector proteins appears to be important for virulence (Jeong et al., 2017). Remarkably, this T4SS is postulated to translocate over 300 effectors during infection, many of which have been shown to target host cellular pathways controlling membrane transport processes (Sherwood and Roy, 2016). Legionella LCVs are designed to escape fusion with lysosomes but comprehensively interact with various endosomal and secretory vesicle trafficking cascades (Isberg et al., 2009; Personnic et al., 2016; Sherwood and Roy, 2016). The LCVs move along microtubules in the host cell and finally merge with the endoplasmic reticulum (ER) (Horwitz et al., 1983; Lu and Clarke, 2005; Robinson and Roy, 2006). In this scenario, translocated effector proteins deregulate crucial factors of host signaling including various phosphatidylinositol lipids (Weber et al., 2006; 2014; Ragaz et al., 2008; Brombacher et al., 2009; Hsu et al., 2012; Toulabi et al., 2013), autophagy components (Choy et al., 2012), $\mathrm{H}^{+}$-ATPase (Xu et al., 2010) as well as the small GTPases Rab1 (Machner and Isberg, 2006; Murata et al., 2006; Schoebel et al., 2010; Itzen and Goody, 2011), Arf1 (Nagai et al., 2002) or Ran (Rothmeier et al., 2013; Simon et al., 2014). The 
composition of LCVs formed in Dictyostelium discoideum was shown by proteomics to involve $>560$ host cell proteins (Brombacher, 2009; Urwyler, 2009; Hilbi et al., 2011). In addition, depletion of the $D$. discoideum OCRL ortholog Dd5P4, encoding an inositol polyphosphate 5-phosphatase, stimulated the intracellular replication of L. pneumophila (Weber et al., 2009, Finsel et al., 2013). Both catalytically active OCRL and Dd5P4 enzymes co-localize with LCVs and enhance the quantity of phosphatidylinositol 4phosphate accessible for binding of other Icm/Dot proteins (Weber et al., 2009). Taken together, $L$. pneumophila utilizes a sophisticated T4SS, manipulating intracellular trafficking machineries for growth and a functional retrograde transport pathway restricts the replication of the pathogen.

Coxiella burnetii

Coxiella burnetii is the causative agent of the zoonosis Q-fever in humans. Coxiella replicates effectively within a lysosome-like compartment called the "Coxiella-containing vacuole" (CCV). Similar to $L$. pneumophila, C. burnetii encodes a Dot/Icm-like T4SS whose function is to modify the host endocytic transport systems and generate the CCV replicative niches (Segal et al., 2005; Voth and Heinzen, 2009). The C. burnetii T4SS orthologs DotH, IcmV and IcmT localize at the bacterial cell poles in infected Vero cell, as shown by immunofluorescence microscopy (IFM) and EM combined with immunogold labeling (Morgan et al., 2010). Although the CCVs exhibit lysosomal capabilities, they display specific features such as homotypic fusion and a cholesterol-enriched limiting membrane, in addition to robustly interacting with autophagosomes (Howe and Heinzen, 2006; Kohler and Roy, 2015). Compelling evidence for the functionality of the Coxiella Dot/Icm subunits came from swapping experiments in L. pneumophila (Chen et al., 2010; Carey et al., 2011). In addition, axenic growth and methods for genetic manipulation were achieved for Coxiella, enabling proof that the Dot/Icm T4SS is essential for growth in CCVs and ultimately identified >130 translocated effector proteins (Zamboni et al., 2003; Zusman et al., 2003; Pan et al., 2008; Beare et al., 2011; Carey et al., 2011; Moffatt et al., 2015). Computer modeling coupled with a validation approach also has facilitated the identification of T4SS secretion signals that may prove useful for discovering novel effector proteins in Legionella and Coxiella (Lifshitz et al., 2013). The endosomal nature 
of CCVs is reflected by the accumulation of late endosomal markers LAMP-1/-2, vasodilator-stimulated phosphoprotein (VASP), as well as the V-ATPase (Voth and Heinzen, 2007; Colonne et al., 2016). Genomewide gene silencing screens using siRNA identified additional host factors including the retromer complex (McDonough et al., 2013). Prominent effector proteins include Cig2, which promotes fusion of autophagosomes with the CCV to maintain this compartment in an autolysosomal maturation stage (Kohler et al., 2016). Another translocated effector, Cig57, co-opts clathrin-mediated trafficking to facilitate the biogenesis of the fusogenic CCVs (Latomanski et al., 2016). In addition, the ankyrin repeat (Ank) family member AnkG was found to interact with the host protein p32, regulating an anti-apoptotic pathway, required for Coxiella's adaptation to mammalian hosts (Lührmann et al., 2010). Finally, C. burnetii inhibits caspase-mediated activation of the NLRP3 inflammasome in macrophages by the effector protein IcaA (Cunha et al., 2015). Thus, Coxiella appears to dampen the inflammasome machinery to avoid clearance by the host immune system.

\section{Bartonella henselae}

Bartonalla henselae is a zoonotic parasite colonizing cats and humans (Dehio, 2005; Regier et al., 2016). Clinical outcomes range from cat scratch disease to persistent bacteremia and vascular tumors. Bartonella exhibits a tropism towards endothelial cells and erythrocytes (Eicher and Dehio, 2012). Binding to the extracellular matrix by adhesins and the activity of a VirB/VirD4-type T4SS by B. henselae induces a massive rearrangement of the host cytoskeleton, which leads to uptake of the bacteria into endothelial cells. Bacterial entry into erythrocytes is mediated by a second T4SS designated Trw, which is followed by intracellular Bartonella growth and persistence. The infection process is aided at different steps by the Bartonella effector proteins (Bep's). All known Bep's carry a C-terminal BID (Bep intracellular delivery) domain acting in part as a T4SS translocation signal (Schulein et al., 2005). Many Beps also have an enzymatic N-terminal FIC (filamentation induced by cAMP) module that facilitates the AMPylation of host cell proteins (Siamer and Dehio, 2015). This AMPylation activity typically triggers the inactivation of yet unknown host cell proteins of 40-50 kDa (Palanivelu et al., 2011). In addition, three effectors (BepD, BepE 
and BepF) harbor tyrosine phosphorylation motifs, which are targeted by host cell kinases similar to CagA described above (Schulein et al., 2005). A proteomics-based screen identified 8 cellular interaction partners (Grb2, Grb7, Shp1, Shp2 and others) of the Bep's, which subvert host cell signaling with roles in proinflammatory responses by activation of NF- $\mathrm{B}$, anti-apoptosis, cell proliferation and others (Selbach et al., 2009). Finally, more recent work established that the VirB/VirD4 T4SS functions as a delivery system for DNA both to other bacteria and human cells (Fernández-González et al., 2011; Schröder et al., 2011). Understanding the functions associated with interkingdom transfer of protein effectors, and potentially DNA substrates, will shed new light on the molecular bases underlying Bartonella - host cell interactions.

\section{Brucella abortus}

Brucella abortus is the causative agent of the zoonosis brucellosis and primarily infects phagocytes (Celli, 2015). The intracellular replication cycle proceeds within the Brucella-containing vacuole (BCV), which initially traffics along the endocytic pathway, acquiring the cellular markers early endosome antigen-1 (EEA-1), Rab5 and Rab7 (Pizarro-Cerdá et al., 1998; Chaves-Olarte et al., 2002; Celli et al., 2003; Starr et al., 2008; Lee et al., 2013). These BCVs fuse rapidly with lysosomes, which provides physicochemical cues for elaboration of the VirB T4SS (Pizarro-Cerdá et al., 1998; Boschiroli et al., 2002; Celli et al., 2003; Starr et al., 2008, Smith et al., 2016). Initially of endosomal origin, BCVs are converted through various VirBdependent steps into organelles derived from the ER that support bacterial proliferation, suggesting these events require the delivery of T4SS effector proteins. Presently, 15 T4SS effector proteins have been identified (de Jong et al., 2008; Marchesini et al., 2011; Myeni et al., 2013; Ke et al., 2015), although only a few are reported to play a clear role in Brucella pathogenesis. Inflammation and IL-6 production triggered by B. abortus infection induces significant ER stress via the T4SS effector protein VceC (Keestra-Gounder et $a l .$, 2016). This process is receptor NOD1/2-, TRAF2- and RIP2-dependent. The association of NOD1 and NOD2 with pro-inflammatory responses induced by the IRE1 $\alpha /$ TRAF2 signaling pathway provides a novel link between innate immunity and ER-stress-induced inflammation. Further studies elucidating the functions of Brucella effector proteins will help clarify the molecular roles of the VirB T4SS during infection. 
Anaplasma phagocytophilum and Ehrlichia chaffeensis

T4SS nanomachines also have been encountered in obligatory intracellular human pathogens such as $A$. phagocytophilum and E. chaffeensis, which respectively cause human granulocytic anaplasmosis and monocytic ehrlichiosis (Ohashi et al., 2002). Both species are transmitted from tick vectors to mammalian hosts where they survive and proliferate in membrane-bound inclusions that lack lysosomal markers and components of NADPH oxidase. These intracellular pathogens depend mostly on host-synthesized nutrients, as they have only a limited number of genes for biosynthesis and metabolism. The first described T4SS effectors were AnkA and Ats-1 from A. phagocytophilum (Lin et al., 2007; Niu et al., 2010), and since then several additional effectors [AM185, AM470, AM705 (AnkA), AM1141] were identified in Anaplasma marginale (Lockwood et al., 2011). To promote their intracellular survival, Anaplasma and Ehrlichia modulate host cell apoptosis by secreting proteins that interfere with this cell death pathway. Strikingly, early studies showed that A. phagocytophilum Ats-1 translocates across the bacterial cell envelope, host cell membrane, and ultimately into mitochondria where it interferes with apoptosis induction (Niu et al., 2010; Niu and Rikihisa, 2013; 2014). More recently, in E. chaffeensis, a T4SS effector similarly was shown to block mitochondrion-mediated host cell apoptosis (Rikihisa, 2015). Ehrlichia chaffeensis infection was further shown to depend on the translocated ehrlichial translocated factor-1 (Etf-1), which induces Rab5regulated autophagy to provide host cytosolic nutrients to the pathogen. The role of Etf-1 in host cell autophagy and infection was confirmed by mutagenesis (Sharma et al., 2017). Etf-1-mediated manipulation of Rab5 is a simple strategy to avoid destruction of the pathogen in lysosomes, obtain membrane components, and establish a homeostatic intra-host cell environment for proliferation (Rikihisa, 2017).

\section{Conclusions and Outlook}

The recent structures of purified T4SS machine subunits and subassemblies continue to generate important molecular details about the paradigmatic systems. Furthermore, cryo-electron tomography yielding the first in situ image of a T4SS represents a promising new direction for structural definition of T4SSs in their native membrane environments (Ghosal et al., 2017). Equally importantly, new T4SSs are being described that 
further highlight the biological diversity of this secretion superfamily. This has been exemplified by discovery that Xanthomonas citri employs a T4SS to kill competing bacteria in the close vicinity in a contact-dependent manner, reminiscent of the type VI secretion killing systems (Souza et al., 2015). An update of this system was presented at a T4SS conference held last December 2016 in Schloss Hirschberg, Germany (www.t4ss-conference.de). This T4SS translocates effectors bearing C-terminal translocation signals, whose bacteriolytic activities degrade peptidoglycan in target cells, but in the donor cell can be neutralized by the synthesis of cognate immunity proteins (Souza et al., 2015; 2016). Intriguingly, more than one thousand Xanthomonas T4SS effectors showing only very limited homology to each other or other proteins were found in protein databases (Souza et al., 2016). This T4SS appears to be widely dispersed among Xanthomonas and related species, making this a possible paradigm for an emerging new family of T4SS-killing machines in bacteria.

In the course of ongoing high-throughput genome sequencing projects, hundreds of putative T4SSs have been identified in obligatory intracellular and other pathogens as well as endosymbionts, e.g., Anaplasma, Rickettsia, Orientia, and Wolbachia spp. (Gillespie et al., 2009; Sonthayanon et al., 2010; Gillespie et al., 2016; Ramirez-Puebla et al., 2016). Most strikingly, the virB/virD4-like genes are often distributed in clusters around the genomes, and the virB2 and virB6 gene families have undergone unprecedented expansions. How these T4SSs contribute to establishment of pathogen or symbiont - host relationships remain ripe areas for further study. Similarly, the accumulating evidence for effector protein transfer by the $89 \mathrm{~K}$ PAI-encoded T4SS in S. suis raises intriguing questions about the extent to which Gram ${ }^{+}$ species deploy T4SSs for interkingdom effector translocation during infection.

As our knowledge of T4SS structures and mechanisms of action deepens, the field is poised to develop effective therapies aimed at suppressing T4SS functions in clinical settings. Indeed, several studies already have targeted the conserved VirB8 homologs as potential drug targets. By screening of a smallmolecule library using Brucella VirB8 as a target, compounds were found that inhibited VirB8 dimerization (Paschos et al., 2011). These also were active against VirB8 from plasmid pKM101, resulting in disruption of VirB8 dimerization and inhibition of conjugation (Casu et al., 2016). A different approach was employed 
for the inhibition of TraM, the VirB8-homolog associated with the pIP501-encoded T4SS as well as other $\mathrm{Gram}^{+}$conjugation machines. Anti-TraM antibodies directed against the VirB8-homolog from plasmid pIP501 considerably reduced the survival of clinical E. faecalis and S. aureus strains harboring a putative T4SS in vitro and in an in vivo mouse infection model (Laverde et al., 2017). A recent study also established the value of testing the efficacy of small molecule inhibitors shown to block the production of phylogenetically unrelated pilus assembly or secretion systems for effects on T4SS biogenesis or function. For example, compounds containing a ring-fused 2-pyridone peptidomimetic fragment that previously had been shown to block the E. coli chaperone-usher pilus pathway also impaired H. pylori Cag pilus production, A. tumefaciens T-DNA transfer, and DNA transfer through the pKM101 and R1-16-encoded conjugation machines (Shaffer et al., 2016).

Finally, recent work by the Llosa and Dehio groups has shown that T4SSs also are viable vectors for delivery of potentially therapeutic DNA into human cells. Escherichia coli and B. henselae donors successfully transfer DNA to human cells where the translocated DNA is stably integrated into the human genome (Schroder et al., 2011; Llosa et al., 2012; Alperi et al., 2013; Gonzalez-Prieto et al., 2017). TrwCrelaxase mediated site-specific DNA integration into the human genome also has been demonstrated, albeit with very low efficiency compared to random integration. TrwC might stabilize the plasmid DNA in the nucleus of the human cell by promoting recircularization of the transferred strand, thus considerably increasing the chances for integration of the DNA by the host machinery (Gonzalez-Prieto et al., 2017). The implementation of state-of-the art metagenomics analyses, cell imaging, and ultrastructural approaches along with the development of translational applications - promises a bright future for the T4SS field.

\section{Acknowledgements}

We thank the many scientists in the T4SS field for their valuable contributions, and we apologize for omissions of published work due to constraints on page limitations. The recent T4SS conference in Schloss Hirschberg, Germany (www.t4ss-conference.de) served as a foundation for this MicroReview. Work in the Backert lab is funded by the German Research Foundation (SFB-1181, project A04), the Christie lab by NIH 
grants R01GM48476 and R21AI105454, the Waksman lab by Wellcome Trust grant 098302, and the Grohmann lab by DLR grant 50WB1466. We thank Adam Redzej from the Waksman lab for assembling the Graphical Abstract picture.

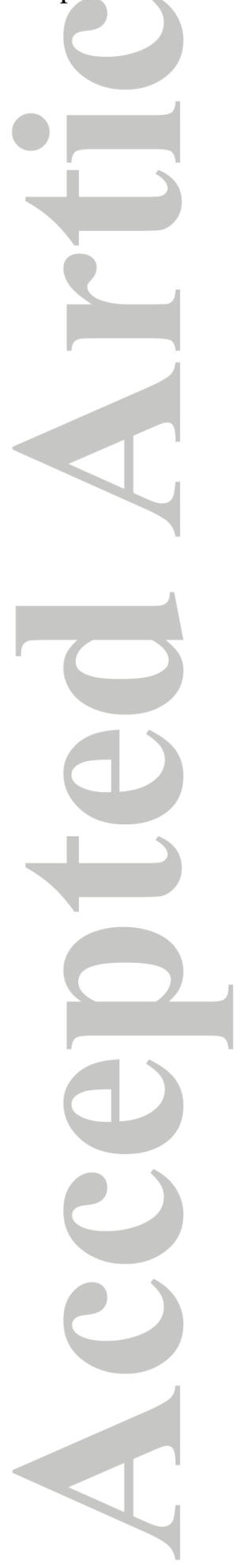




\section{References}

Alperi, A., Larrea, D., Fernández-González, E., Dehio, C., Zechner, E.L., and Llosa M. (2013) A translocation motif in relaxase TrwC specifically affects recruitment by its conjugative type IV secretion system. J Bacteriol 195: 4999-5006.

Alvarez-Martinez, C.E., and Christie, P.J. (2009) Biological diversity of prokaryotic type IV secretion systems. Microbiol Mol Biol Rev 73: 775-808.

Arends, K., Celik, E.-K., Probst, I., Goessweiner-Mohr, N., Fercher, C., Grumet, L., et al. (2013) TraG encoded by the pIP501 type IV secretion system is a two domain peptidoglycan degrading enzyme essential for conjugative transfer. J Bacteriol 195: 4436-4444.

Arutyunov, D., and Frost, L.S. (2013) F conjugation: back to the beginning. Plasmid 70: 18-32.

Atmakuri, K., Cascales, E. Burton, O.T., Banta, L.M., and Christie, P.J. (2007) Agrobacterium ParA/MinDlike VirC1 spatially coordinates early conjugative DNA transfer reactions. EMBO J 26: 2540-2551.

Atmakuri, K., Cascales, E., and Christie, P.J. (2004) Energetic components VirD4, VirB11 and VirB4 mediate early DNA transfer reactions required for bacterial type IV secretion. Mol Microbiol 54: 11991211.

Auchtung, J.M., Aleksanyan, N., Bulku, A., and Berkmen, M.B. (2016) Biology of ICEBs1, an integrative and conjugative element in Bacillus subtilis. Plasmid 86: 14-25.

Babic, A., Lindner, A.B., Vulic, M., Stewart, E.J., and Radman, M. (2008) Direct visualization of horizontal gene transfer. Science 319: 1533-1536.

Backert, S., Fronzes, R., and Waksman, G. (2008) VirB2 and VirB5 proteins: specialized adhesins in bacterial type-IV secretion systems? Trends Microbiol 16: 409-413.

Backert, S., and Meyer, T.F. (2006) Type IV secretion systems and their effectors in bacterial pathogenesis. Curr Opin Microbiol 9: 207-217.

Backert, S., Tegtmeyer, N., and Fischer, W. (2015) Composition, structure and function of the Helicobacter pylori cag pathogenicity island encoded type IV secretion system. Future Microbiol 10: 955-965. 
Banta, L.M., Kerr, J.E., Cascales, E., Giuliano, M.E., Bailey, M.E., McKay, C., et al. (2011) An Agrobacterium VirB10 mutation conferring a type IV secretion system gating defect. J Bacteriol 193: 2566-2574.

Bantwal, R., Bannam, T.L., Porter, C.J., Quinsey, N.S., Lyras, D., Adams, V., et al. (2012) The peptidoglycan hydrolase TcpG is required for efficient conjugative transfer of pCW3 in Clostridium perfringens. Plasmid 67:139-147.

Barden, S., Lange, S., Tegtmeyer, N., Conradi, J., Sewald, N., Backert, S., et al. (2013) A helical RGD motif promoting cell adhesion: crystal structures of the Helicobacter pylori type IV secretion system pilus protein CagL. Structure 21: 1931-1941.

Beare, P.A., Gilk, S.D., Larson, C.L., Hill, J., Stead, C.M., Omsland, A., et al. (2011) Dot/Icm type IVB secretion system requirements for Coxiella burnetii growth in human macrophages. MBio 2: e00175-

11.

Berger, B.R., and Christie, P.J. (1993) The Agrobacterium tumefaciens virB4 gene product is an essential virulence protein requiring an intact nucleoside triphosphate-binding domain. J Bacteriol 175: 17231734.

Berger, B.R., and Christie, P.J. (1994) Genetic complementation analysis of the Agrobacterium tumefaciens virB operon: virB2 through virB11 are essential virulence genes. J Bacteriol 176: 3646-3660.

Bhatty, M., Camacho, M.I., Gonzalez-Rivera,C., Frank, K.L, Dale, J.L., Manias, D.A., et al. (2017) PrgU: a suppressor of sex pheromone toxicity in Enterococcus faecalis. Mol Microbiol. 103: 398-412.

Bhatty, M., Cruz, M.R., Frank, K.L, Gomez, J.A., Andrade, F., Garsin, D.A., et al. (2015) Enterococcus faecalis $\mathrm{pCF} 10$-encoded surface proteins $\operatorname{Prg} \mathrm{A}, \operatorname{PrgB}$ (aggregation substance) and $\operatorname{PrgC}$ contribute to plasmid transfer, biofilm formation and virulence. Mol Microbiol 95: 660-677.

Bhatty, M., Laverde Gomez, J.A., and Christie, P.J. (2013) The expanding bacterial type IV secretion lexicon. Res Microbiol 164: 620-639.

Boschiroli, M.L., Ouahrani-Bettache, S., Foulongne, V., Michaux-Charachon, S., Bourg, G., AllardetServent, A., et al. (2002) Type IV secretion and Brucella virulence. Vet Microbiol 90: 341-348. 
Brombacher, E., Urwyler, S., Ragaz, C., Weber, S.S., Kami, K., Overduin, M., et al. (2009) Rab1 guanine nucleotide exchange factor SidM is a major phosphatidylinositol 4-phosphate-binding effector protein of Legionella pneumophila. J Biol Chem 284: 4846-4856.

Cabezón, E., Ripoll-Rozada, J., Peña, A., de la Cruz, F., and Arechaga, I. (2015) Towards an integrated model of bacterial conjugation. FEMS Microbiol Rev 39: 81-95.

Carey, K.L., Newton, H.J., Lührmann, A., and Roy, C.R. (2011) The C. burnetii Dot/Icm system delivers a unique repertoire of type IV effectors into host cells and is required for intracellular replication. PLoS Pathog 7: e1002056.

Carraro, N., and Burrus, V. (2014) Biology of three ICE Families: SXT/R391, ICEBs1, and ICESt1/ICESt3. Microbiol Spectr 2 doi: 10.1128/microbiolspec.MDNA3-0008-2014.

Cascales, E., and Christie, P.J. (2004) Definition of a bacterial type IV secretion pathway for a DNA substrate. Science 304: 1170-1173.

Casu, B., Smart, J., Hancock, M.A., Smith, M., Sygusch, J., and Baron, C. (2016) Structural analysis and inhibition of TraE from the pKM101 type IV secretion system. J Biol Chem 291: 23817-23829.

Celli, J. (2015) The changing nature of the Brucella-containing vacuole. Cell Microbiol 17: 951-958.

Celli, J., de Chastellier, C., Franchini, D.M., Pizarro-Cerda, J., Moreno, E., and Gorvel, J.P. (2003) Brucella evades macrophage killing via VirB-dependent sustained interactions with the endoplasmic reticulum. $J$ Exp Med 198: 545-556.

Chandran, V., Fronzes, R., Duquerroy, S., Cronin, N., Navaza, J., and Waksman, G. (2009) Structure of the outer membrane complex of a type IV secretion system. Nature 462: 1011-1015.

Chandran Darbari, V., and Waksman, G. (2015) Structural biology of bacterial type IV secretion systems. Annu Rev Biochem 84: 603-629.

Chen, C., Banga, S., Mertens, K., Weber, M.M., Gorbaslieva, I., Tan, Y., et al. (2010) Large-scale identification and translocation of type IV secretion substrates by C. burnetii. Proc Natl Acad Sci USA 107: 21755-21760. 
Choy, A., Dancourt, J., Mugo, B., O'Connor, T.J., Isberg, R.R., Melia, T.J., et al. (2012) The Legionella effector RavZ inhibits host autophagy through irreversible Atg8 deconjugation. Science 338: 10721076.

Christie, E., Guzmán-Verri, C., Méresse, S., Desjardins, M., Pizarro-Cerdá, J., Badilla, J., et al. (2002) Activation of Rho and Rab GTPases dissociates Brucella abortus internalization from intracellular trafficking. Cell Microbiol 4: 663-676.

Christie, P.J. (2016) The Mosaic Type IV Secretion Systems. EcoSalPlus 7 doi:10.1128/ecosalplus.ESP0020-2015.

Clewell, D.B., Weaver, K.E., Dunny, G.M., Coque, T.M., Francia, M.V., and Hayes, F. (2014) Extrachromosomal and Mobile Elements in Enterococci: Transmission, Maintenance, and Epidemiology. In: Gilmore, M.S., Clewell, D.B., Ike, Y., Shankar, N., editors. Enterococci: From Commensals to Leading Causes of Drug Resistant Infection. Boston: Massachusetts Eye and Ear Infirmary.

Colonne, P.M., Winchell, C.G., Graham, J.G., Onyilagha, F.I., MacDonald, L.J., Doeppler, H.R., et al. (2016) Vasodilator-stimulated phosphoprotein activity is required for Coxiella burnetii growth in human macrophages. PLoS Pathog 12: e1005915.

Costa, T.R., Ilangovan, A., Ukleja, M., Redzej, A., Santini, J.M., Smith, T.K., Egelman, E.H., and Waksman, G. (2016) Structure of the bacterial sex F pilus reveals an assembly of a stoichiometric protein-phospholipid complex. Cell 166: 1436-1444.e10.

Cunha, L.D., Ribeiro, J.M., Fernandes, T.D., Massis, L.M., Khoo, C.A., Moffatt, J.H., et al. (2015) Inhibition of inflammasome activation by $C$. burnetii type IV secretion system effector IcaA. Nat Commun 6: 10205 .

Dehio, C. (2005) Bartonella-host-cell interactions and vascular tumour formation. Nat Rev Microbiol 3: 621631. 
De Jong, M.F., Sun, Y.H., den Hartigh, A.B., van Dijl, J.M., and Tsolis, R.M. (2008) Identification of VceA and $\mathrm{VceC}$, two members of the $\mathrm{VjbR}$ regulon that are translocated into macrophages by the Brucella type IV secretion system. Mol Microbiol 70: 1378-1396.

de la Cruz, F., Frost, L.S., Meyer, R.J., and Zechner, E.L. (2010) Conjugative DNA metabolism in Gramnegative bacteria. FEMS Microbiol Rev 34: 18-40.

DeWitt, T., and Grossman, A.D. (2014) The bifunctional cell wall hydrolase CwlT is needed for conjugation of the integrative and conjugative element ICEBs 1 in Bacillus subtilis and B. anthracis. J Bacteriol 196: $1588-1596$.

Dürrenberger, M.B., Villiger, W., and Bächi, T. (1991) Conjugational junctions: morphology of specific contacts in conjugating Escherichia coli bacteria. J Struct Biol 107: 146-156.

Eicher, S.C., and Dehio, C. (2012) Bartonella entry mechanisms into mammalian host cells. Cell Microbiol 14: 1166-1173.

Eisenbrandt, R., Kalkum, M., Lai, E.M., Lurz, R., Kado, C.I., and Lanka, E. (1999) Conjugative pili of IncP plasmids, and the Ti plasmid T pilus are composed of cyclic subunits. J Biol Chem 274: 22548-22555.

Fercher, C., Probst, I., Goessweiner-Mohr, N., Arends, K., Grohmann, E., Meyer, N.-H., et al. (2016) VirB8like protein TraH is crucial for DNA transfer in Enterococcus faecalis. Sci Rep 6: 24643.

Fernández-González, E., de Paz, H.D., Alperi, A., Agúndez, L., Faustmann, M., Sangari, F.J., et al. (2011) Transfer of R388 derivatives by a pathogenesis-associated type IV secretion system into both bacteria and human cells. J Bacteriol 193: 6257-6265.

Fernández-González, E., and Backert, S. (2014) DNA transfer in the gastric pathogen Helicobacter pylori. J Gastroenterol 49:594-604.

Finsel, I., Ragaz, C., Hoffmann, C., Harrison, C.F., Weber, S., van Rahden, V.A., et al. (2013) The Legionella effector RidL inhibits retro-grade trafficking to promote intracellular replication. Cell Host Microbe 14: 38-50. 
Fischer, W., Püls, J., Buhrdorf, R., Gebert, B., Odenbreit, S., and Haas, R. (2001) Systematic mutagenesis of the H. pylori cag pathogenicity island: essential genes for CagA translocation in host cells and induction of interleukin-8. Mol Microbiol 42: 1337-1348.

Franco, A.T., Johnston, E., Krishna, U., Yamaoka, Y., Israel, D.A., Nagy, T.A., et al. (2008) Regulation of gastric carcinogenesis by H. pylori virulence factors. Cancer Res 68: 379-387.

Frick-Cheng, A.E., Pyburn, T.M., Voss, B.J., McDonald, W.H., Ohi, M.D., and Cover, T.L. (2016) Molecular and structural analysis of the $H$. pylori cag type IV secretion system core complex. MBio 12: e02001-15.

Fronzes, R., Schafer, E., Wang, L., Saibil, H.R., Orlova, E.V., and Waksman, G. (2009) Structure of a type IV secretion system core complex. Science 323: 266-268.

Frost, L.S., and Koraimann, G. (2010) Regulation of bacterial conjugation: balancing opportunity with adversity. Future Microbiol 5: 1057-1071.

Gall, A., Gaudet, R.G., Gray-Owen, S.D., and Salama, N.R. (2017) TIFA signaling in gastric epithelial cells initiates the cag type 4 secretion system-dependent innate immune response to Helicobacter pylori infection. MBio 8: pii: e01168-17.

Garcillan-Barcia, M.P., Francia, M.V., and de la Cruz, F. (2009) The diversity of conjugative relaxases and its application in plasmid classification. FEMS Microbiol Rev 33: 657-687.

Ghosal, D., Chang, Y.W., Jeong, K.C., Vogel, J.P., and Jensen, G.J. (2017) In situ structure of the Legionella Dot/Icm type IV secretion system by electron cryotomography. EMBO Rep 18: 726-732.

Gillespie, J.J., Ammerman, N.C., Dreher-Lesnick, S.M., Rahman, M.S., Worley, M.J., Setubal, J.C., et al. (2009) An anomalous type IV secretion system in Rickettsia is evolutionarily conserved. PLoS One 4: e4833.

Gillespie, J.J., Brayton, K.A., Williams, K.P., Diaz, M.A., Brown, W.C., Azad, A.F., et al. (2010) Phylogenomics reveals a diverse Rickettsiales type IV secretion system. Infect Immun 78: 1809-1823. 
Gillespie, J.J., Phan, I.Q., Driscoll, T.P., Guillotte, M.L., Lehman, S.S., Rennoll-Bankert, K.E., et al. (2016) The Rickettsia type IV secretion system: unrealized complexity mired by gene family expansion. Pathog Dis 201674.

Goessweiner-Mohr, N., Grumet L., Arends, K., Pavkov-Keller, T., Gruber, C.C., Gruber, K., et al. (2013a) The 2.5 A structure of the Enterococcus conjugation protein TraM resembles VirB8 type IV secretion proteins. J Biol Chem 288: 2018-2028.

Goessweiner-Mohr, N., Arends, K., Keller W., and Grohmann, E. (2013b) Conjugative type IV secretion in Gram-positive bacteria. Plasmid 70: 289-302.

Goessweiner-Mohr, N., Arends, K., Keller, W., and Grohmann, E. (2014a) Conjugation in Gram-positive bacteria. Microbiol Spectrum 2: PLAS-0004-2013.

Goessweiner-Mohr, N., Eder, M., Hofer, G., Fercher, C., Arends, K., Birner-Gruenberger, R., et al. (2014b) Structure of the double-stranded DNA-binding type IV secretion protein TraN from Enterococcus. Acta Crystallogr D Biol Crystallogr 70: 2376-2389.

Gomis-Rüth, F.X., Moncalián, G., Pérez-Luque, R., González, A., Cabezón, E., de la Cruz, F., et al. (2001) The bacterial conjugation protein TrwB resembles ring helicases and F1-ATPase. Nature 409: 637641.

González-Prieto, C., Gabriel, R., Dehio, C., Schmidt, M., and Llosa, M. (2017) The conjugative relaxase TrwC promotes integration of foreign DNA in the human genome. Appl Environ Microbiol 83. pii: e00207-17.

Gordon, J.E., Costa, T.R.D., Patel, R.S., Gonzalez-Rivera, C., Sarkar, M.K., Orlova, E.V., et al. (2017) Use of chimeric type IV secretion systems to define contributions of outer membrane subassemblies for contact-dependent translocation. Mol Microbiol 105: 273-293.

Grohmann, E., Goessweiner-Mohr, N., and Brantl, S. (2016) DNA-binding proteins regulating pIP501 transfer and replication. Review. Front Mol Biosci 11.8.2016. 
Gruber, C.J, Lang, S., Rajendra, V.K.H., Nuk, M., Raffl, S., Schildbach, J.F., et al. (2016) Conjugative DNA transfer is enhanced by plasmid R1 partitioning proteins. Front Mol Biosci 3. doi: 10.3389/fmolb.2016.00032.

Guglielmini, J., de la Cruz, F., and Rocha, E.P. (2013) Evolution of conjugation and type IV secretion systems. Mol Biol Evol 30: 315-331.

Guglielmini, J., Neron, B., Abby S.S., Garcillan-Barcia, M.P., de la Cruz F., and Rocha, E.P. (2014) Key components of the eight classes of type IV secretion systems involved in bacterial conjugation or protein secretion. Nucleic Acids Res 42: 5715-5727.

Hare, S., Bayliss, R., Baron, C., and Waksman, G. (2006) A large domain swap in the VirB11 ATPase of Brucella suis leaves the hexameric assembly intact. J Mol Biol 360: 56-66.

Hayashi, T., Senda, M., Morohashi, H., Higashi, H., Horio, M., Kashiba, Y., et al. (2012) Tertiary structurefunction analysis reveals the pathogenic signaling potentiation mechanism of $H$. pylori oncogenic effector CagA. Cell Host Microbe 12: 20-33.

Higashi, H., Tsutsumi, R., Muto, S., Sugiyama, T., Azuma, T., Asaka, M., et al. (2002) SHP-2 tyrosine phosphatase as an intracellular target of $H$. pylori CagA protein. Science 295: 683-686.

Hilbi, H., Weber, S., and Finsel, I. (2011) Anchors for effectors: subversion of phospho-inositide lipids by Legionella. Front Microbiol 2: 91.

Hofreuter, D., Odenbreit, S., Püls, J., Schwan, D., and Haas, R. (2000) Genetic competence in Helicobacter pylori: mechanisms and biological implications. Res Microbiol. 151: 487-491.

Hofreuter, D., Odenbreit, S., Henke, G., and Haas, R. (1998) Natural competence for DNA transformation in Helicobacter pylori: identification and genetic characterization of the comB locus. Mol Microbiol 28: 1027-1038.

Hofreuter, D., Karnholz, A., and Haas, R. (2003) Topology and membrane interaction of Helicobacter pylori ComB proteins involved in natural transformation competence. Int J Med Microbiol 293: 153-165.

Horwitz, M.A. (1983) Formation of a novel phagosome by the Legionnaires' disease bacterium (Legionella pneumophila) in human monocytes. J Exp Med 158: 1319-1331. 
Hospenthal, M.K., Costa, T.R.D., and Waksman, G. (2017) A comprehensive guide to pilus biogenesis in Gram-negative bacteria. Nat Rev Microbiol 15: 365-379.

Howe, D., and Heinzen, R.A. (2006) Coxiella burnetii inhabits a cholesterol-rich vacuole and influences cellular cholesterol metabolism. Cell Microbiol 8: 496-507.

Hsu, F., Zhu, W., Brennan, L., Tao, L., Luo, Z.Q., and Mao, Y. (2012) Structural basis for substrate recognition by a unique Legionella phosphoinositide phosphatase. Proc Natl Acad Sci USA 109: $13567-13572$.

Ilangovan, A., Kay, C.W.M., Roier, S., El Mkami, H., Salvadori, E., Zechner, E.L., et al. (2017) Cryo-EM structure of a relaxase reveals the molecular basis of DNA unwinding during bacterial conjugation. Cell 169: 708-721.

Isberg, R.R., O'Connor, T.J., and Heidtman, M. (2009) The Legionella pneumophila replication vacuole: making a cozy niche inside host cells. Nat Rev Microbiol 7: 13-24.

Itzen, A. and Goody, R.S. (2011) Covalent coercion by Legionella pneumophila. Cell Host Microbe 10: 8991.

Jakubowski, S.J., Kerr, J.E., Garza, I., Krishnamoorthy, V., Bayliss, R., Waksman, G., et al. (2009) Agrobacterium VirB10 domain requirements for type IV secretion and T pilus biogenesis. Mol Microbiol 71: 779-794.

Javaheri, A., Kruse, T., Moonens, K., Mejías-Luque, R., Debraekeleer, A., Asche, C.I., et al. (2016) Helicobacter pylori adhesin HopQ engages in a virulence-enhancing interaction with human CEACAMs. Nat Microbiol 2: 16189.

Jeong, K.C., Ghosal, D., Chang, Y.W., Jensen, G.J., and Vogel, J.P. (2017) Polar delivery of Legionella type IV secretion system substrates is essential for virulence. Proc Natl Acad Sci USA 107: 18997-9001.

Jiang, X., Yang, Y., Zhou, J., Zhu, L., Gu, Y., Zhang, X., et al. (2016) Roles of the putative type IV-like secretion system key component VirD4 and PrsA in pathogenesis of Streptococcus suis type 2. Front Cell Infect Microbiol 6: 172. 
Johnson, C.M., and Grossman, A.D. (2015) Integrative and Conjugative Elements (ICEs): What they do and how they work. Annu Rev Genet 49: 577-601.

Kaplan-Türköz, B., Jiménez-Soto, L.F., Dian, C., Ertl, C., Remaut, H., Louche, A., et al. (2012) Structural insights into H. pylori oncoprotein CagA interaction with $\beta_{1}$ integrin. Proc Natl Acad Sci 109: 1464014645.

Ke, Y., Wang, Y., Li, W., Chen, Z. (2015) Type IV secretion system of Brucella spp. and its effectors. Front Cell Infect Microbiol 5: 72.

Keestra-Gounder, A.M., Byndloss, M.X., Seyffert, N., Young, B.M., Chávez-Arroyo, A., Tsai, A.Y., et al. (2016) NOD1 and NOD2 signaling links ER stress with inflammation. Nature 532: 394-397.

Kohler, P.L., Chan, Y.A., Hackett, K.T., Turner, N., Hamilton, H.L., Cloud-Hansen, K.A., et al. (2013) Mating pair formation homologue TraG is a variable membrane protein essential for contactindependent type IV secretion of chromosomal DNA by Neisseria gonorrhoeae. J Bacteriol 195: 16661679.

Kohler, L.J., and Roy, C.R. (2015) Biogenesis of the lysosome-derived vacuole containing Coxiella burnetii. Microbes Infect 17: 766-771.

Kohler, L.J., Reed, S.C., Sarraf, S.A., Arteaga, D.D., Newton, H.J., and Roy, C.R. (2016) Effector protein Cig2 decreases host tolerance of infection by directing constitutive fusion of autophagosomes with the Coxiella-containing vacuole. MBio 7: pii: e01127-16.

Kohler, V., Probst, I., Aufschnaiter, A., Büttner, S., Schaden, L., Rechberger, G.N., et al. (2017) Conjugative type IV secretion in Gram-positive pathogens: TraG, a lytic transglycosylase and endopeptidase, interacts with translocation channel protein TraM. Plasmid 91:9-18.

Königer, V., Holsten, L., Harrison, U., Busch, B., Loell, E., Zhao, Q., et al. (2016) Helicobacter pylori exploits human CEACAMs via HopQ for adherence and translocation of CagA. Nat Microbiol 2: 16188. 
Koraimann, G., and Wagner, M.A. (2014) Social behavior and decision making in bacterial conjugation. Front Cell Infect Microbiol 4: 54.

Krüger, N.-J., and Stingl, K. (2011) Two steps away from novelty - principles of bacterial DNA uptake. Mol Microbiol 80: 860-867.

Kubori, T., Koike, M., Bui, X.T., Higaki, S., Aizawa, S., and Nagai, H. (2014) Native structure of a type IV secretion system core complex essential for Legionella pathogenesis. Proc Natl Acad Sci USA 111: 11804-11809.

Kwak, M.J., Kim, J.D., Kim, H., Kim, C., Bowman, J.W., Kim, S., et al. (2017) Architecture of the type IV coupling protein complex of Legionella pneumophila. Nat Microbiol 2: 17114.

Kwok, T., Zabler, D., Urman, S., Rohde, M., Hartig, R., Wessler, S., et al. (2007) Helicobacter exploits integrin for type IV secretion and kinase activation. Nature 449: 862-866.

Lang, S., Gruber, C.J., Raffl, S., Reisner, A., Zechner, E.L. (2014) Common requirement for the relaxosome of plasmid R1 in multiple activities of the conjugative type IV secretion system. J Bacteriol 196: 21082121.

Latomanski, E.A., Newton, P., Khoo, C.A., and Newton, H.J. (2016) The effector Cig57 hijacks FCHOmediated vesicular trafficking to facilitate intracellular replication of Coxiella burnetii. PLoS Pathog 12: e1006101.

Laverde Gomez, J.A., Bhatty, M., and Christie, P.J. (2014) PrgK, a multidomain peptidoglycan hydrolase, is essential for conjugative transfer of the pheromone-responsive plasmid pCF10. J Bacteriol 196: 527539.

Laverde, D., Probst, I., Romero-Saavedra, F., Kropec, A., Wobser, D., Keller, W., et al. (2017) Targeting type IV secretion system proteins to combat multiresistant Gram-Positive pathogens. J Infect Dis 215: 1836-1845.

Lawley, T.D., Klimke, W.A., Gubbins, M.J., and Frost, L.S. (2003) F factor conjugation is a true type IV secretion system. FEMS Microbiol Lett. 224: 1-15. 
Lee, J.J., Kim, D.G., Kim, D.H., Simborio, H.L., Min, W., Lee, H.J., et al. (2013) Interplay between clathrin and Rab5 controls the early phagocytic trafficking and intracellular survival of Brucella abortus within HeLa cells. J Biol Chem 288: 28049-28057.

Leonard, T.A., Moller-Jensen, J., and Lowe, J. (2005). Towards understanding the molecular basis of bacterial DNA segregation. Philos Trans R Soc Lond B Biol Sci 360: 523-535.

Leonetti, C.T., Hamada, M.A., Laurer, S.J., Broulidakis, M.P., Swerdlow, K.J., Lee, C.A., et al. (2015) Critical components of the conjugation machinery of the Integrative and Conjugative Element ICEBs1 of Bacillus subtilis. J Bacteriol 197: 2558-2567.

Li, M., Shen, X., Yan, J., Han, H., Zheng, B., Liu, D., et al. (2011) GI-type T4SS-mediated horizontal transfer of the $89 \mathrm{~K}$ pathogenicity island in epidemic Streptococcus suis serotype 2. Mol Microbiol 79: 1670-1683.

Li, F., Alvarez-Martinez, C., Chen, Y., Choi, K.J., Yeo, H.J., and Christie, P.J. (2012) Enterococcus faecalis PrgJ, a VirB4-like ATPase, mediates pCF10 conjugative transfer through substrate binding. J Bacteriol 194: 4041-4051.

Lifshitz Z, Burstein D, Peeri M, Zusman T, Schwartz K, Shuman HA, et al. (2013) Computational modeling and experimental validation of the Legionella and Coxiella virulence-related type-IVB secretion signal. Proc Natl Acad Sci USA 110: E707-15.

Lin, M., den Dulk-Ras, A., Hooykaas, P.J. and Rikihisa, Y. (2007) Anaplasma phagocytophilum AnkA secreted by type IV secretion system is tyrosine phosphorylated by Abl-1 to facilitate infection. Cell Microbiol 9: 2644-2657.

Lipscomb, G.L., Stirrett, K., Schut, G.J., Yang, F., Jenney, F.E. Jr., Scott, R.A. et al. (2011) Natural competence in the hyperthermophilic archaeon Pyrococcus furiosus facilitates genetic manipulation: construction of markerless deletions of genes encoding the two cytoplasmic hydrogenases. Appl Env Microbiol 77: 2232-2238.

Llosa, M., and de la Cruz, F. (2005) Bacterial conjugation: a potential tool for genomic engineering. Res Microbiol 156: 1-6. 
Llosa, M., Schroder, G., and Dehio, C. (2012) New perspectives into bacterial DNA transfer to human cells. Trends Microbiol 20: 355-359.

Lockwood, S., Voth, D.E., Brayton, K.A., Beare, P.A., Brown, W.C., Heinzen, R.A., et al. (2011) Identification of Anaplasma marginale type IV secretion system effector proteins. PLoS One 6: e27724.

Low, H.H., Gubellini, F., Rivera-Calzada, A.F., Braun, N., Connery, S., Dujeancourt, A., et al. (2014) Structure of a type IV secretion system. Nature 508: 550-553.

Lu, H., and Clarke, M. (2005) Dynamic properties of Legionella-containing phagosomes in Dictyostelium amoebae. Cell Microbiol 7: 995-1007.

Lührmann, A., Nogueira, C.V., Carey, K.L., and Roy, C.R. (2010) Inhibition of pathogen-induced apoptosis by a Coxiella burnetii type IV effector protein. Proc Natl Acad Sci USA 107: 8997-9001.

Machner, M.P., and Isberg, R.R. (2006) Targeting of host Rab GTPase function by the intravacuolar pathogen Legionella pneumophila. Dev Cell 11: 47-56.

Marchesini, M.I., Herrmann, C.K., Salcedo, S.P., Gorvel, J.P., and Comerci, D.J. (2011) In search of Brucella abortus type IV secretion substrates: screening and identification of four proteins translocated into host cells through VirB system. Cell Microbiol 13: 1261-1274.

McDonough, J.A., Newton, H.J., Klum, S., Swiss R, Agaisse H, and Roy CR. (2013) Host pathways important for Coxiella burnetii infection revealed by genome-wide RNA interference screening. MBio 4: $\mathrm{e} 00606-12$.

Mimuro, H., Suzuki, T., Tanaka, J., Asahi,M., Haas, R., and Sasakawa, C. (2002) Grb2 is a key mediator of H. pylori CagA protein activities. Mol Cell 10: 745-755.

Moffatt, J.H., Newton, P., and Newton, H.J. (2015) Coxiella burnetii: turning hostility into a home. Cell Microbiol 17: 621-631.

Morgan, J.K., Luedtke, B.E., and Shaw, E.I. (2010) Polar localization of the Coxiella burnetii type IVB secretion system. FEMS Microbiol Lett 305: 177-183. 
Mueller, D., Tegtmeyer, N., Brandt, S., Yamaoka, Y., De Poire, E., Sgouras, D., et al. (2012) c-Src and c-Abl kinases control hierarchic phosphorylation and function of the CagA effector protein in Western and East Asian Helicobacter pylori strains. J Clin Invest 122: 1553-1566.

Murata, T., Delprato, A., Ingmundson, A., Toomre, D.K., Lambright, D.G., and Roy, C.R. (2006) The Legionella pneumophila effector protein DrrA is a Rab1 guanine nucleotide-exchange factor. Nat Cell Biol 8: 971-977.

Myeni, S., Child, R., Ng, T.W., Kupko, J.J. $3^{\text {rd }}$, Wehrly, T.D., Porcella, S.F., et al. (2013) Brucella modulates secretory trafficking via multiple type IV secretion effector proteins. PLoS Pathog 9: e1003556.

Nagai, H., Kagan, J.C., Zhu, X., Kahn, R.A., and Roy, C.R. (2002) A bacterial guanine nucleotide exchange factor activates ARF on Legionella phagosomes. Science 295: 679-682.

Nagai, H., and Kubori, T. (2011) Type IVB secretion systems of Legionella and other Gram-negative bacteria. Front Microbiol 2: 136.

Nešić, D., Buti, L., Lu, X., and Stebbins, C.E. (2014) Structure of the Helicobacter pylori CagA oncoprotein bound to the human tumor suppressor ASPP2. Proc Natl Acad Sci USA 111: 1562-1567.

Niu, H., Kozjak-Pavlovic, V., Rudel T., and Rikihisa, Y. (2010) Anaplasma phagocytophilum Ats-1 is imported into host cell mitochondria and interferes with apoptosis induction. PLoS Pathog 6: e1000774.

Niu, H., and Rikihisa, Y. (2013) Ats-1: a novel bacterial molecule that links autophagy to bacterial nutrition. Autophagy 9: 787-788.

Niu, H., and Rikihisa, Y. (2014) Investigating interference with apoptosis induction by bacterial proteins. Methods Mol Biol 1197: 169-184.

Obergfell, K.P., and Seifert, H.S. (2015) Mobile DNA in the pathogenic Neisseria. Microbiol Spectr 3: MDNA3-0015-2014.

Ohashi, N., Zhi, N., Lin, Q., and Rikihisa, Y. (2002) Characterization and transcriptional analysis of gene clusters for a type IV secretion machinery in human granulocytic and monocytic ehrlichiosis agents. Infect Immun 70: 2128-2138. 
Ohnishi, N., Yuasa, H., Tanaka, S., Sawa, H., Miura, M., Matsui, A., et al. (2008) Transgenic expression of Helicobacter pylori CagA induces gastrointestinal and hematopoietic neoplasms in mouse. Proc Natl Acad Sci USA 105: 1003-1008.

Pachulec, E., Siewering, K., Bender, T., Heller, E.M., Salgado-Pabon, W., Schmoller, S.K., et al. (2014) Functional analysis of the gonococcal genetic island of Neisseria gonorrhoeae. PLOs One 9: e109613.

Palanivelu, D.V., Goepfert, A., Meury, M., Guye, P., Dehio, C., and Schirmer, T. (2011) Fic domaincatalyzed adenylylation: insight provided by the structural analysis of the type IV secretion system effector BepA. Protein Sci 20: 492-499.

Pan, X., Lührmann, A., Satoh, A., Laskowski-Arce, M.A., and Roy, C.R. (2008) Ankyrin repeat proteins comprise a diverse family of bacterial type IV effectors. Science 320: 1651-1654.

Paschos, A., den Hartigh, A., Smith, M.A., Atluri, V.L., Sivanesan, D., Tsolis, R.M., et al. (2011) An in vivo high-throughput screening approach targeting the type IV secretion system component VirB8 identified inhibitors of Brucella abortus 2308 proliferation. Infect Immun 79: 1033-1043.

Personnic, N., Bärlocher, K., Finsel, I., and Hilbi, H. (2016) Subversion of retrograde trafficking by translocated pathogen effectors. Trends Microbiol 24: 450-462.

Pizarro-Cerdá, J., Moreno, E., Sanguedolce, V., Mege, J.L., and Gorvel, J.P. (1998) Virulent Brucella abortus prevents lysosome fusion and is distributed within autophagosome-like compartments. Infect Immun 66: 2387-2392.

Porter, C.J., Bantwal, R., Bannam, T.L., Rosado, C.J., Pearce, M.C., Adams, V., et al. (2012) The conjugation protein TcpC from Clostridium perfringens is structurally related to the type IV secretion system protein VirB8 from Gram-negative bacteria. Mol Microbiol 83: 275-288.

Ragaz, C., Pietsch, H., Urwyler, S., Tiaden, A., Weber, S.S., and Hilbi, H. (2008) The Legionella pneumophila phosphatidylinositol-4 phosphate-binding type IV substrate SidC recruits endoplasmic reticulum vesicles to a replication-permissive vacuole. Cell Microbiol 10: 2416-2433.

Ramírez-Puebla, S.T., Ormeño-Orrillo, E., Vera-Ponce de León, A., Lozano, L., Sanchez-Flores, A., Rosenblueth, M., et al. (2016) Genomes of candidatus Wolbachiabourtzisii wDacA and 
candidatus Wolbachia pipientis wDacB from the cochineal insect Dactylopius coccus (Hemiptera: Dactylopiidae). G3 (Bethesda) 6: 3343-3349.

Redzej, A., Ilangovan, A., Lang, S., Gruber, C.J., Topf, M., Zangger, K., et al. (2013) Structure of a translocation signal domain mediating conjugative transfer by type IV secretion systems. Mol Microbiol 89: 324-333.

Redzej, A., Ukleja, M., Connery, S., Trokter, M., Felisberto-Rodrigues, C., Cryar, A., et al. (2017) Structure of a VirD4 coupling protein bound to a VirB type IV secretion machinery. EMBO J pii: e201796629.

Regier, Y., O Rourke, F., and Kempf, V.A. (2016) Bartonella spp. - a chance to establish One Health concepts in veterinary and human medicine. Parasit Vectors 9: 261.

Rikihisa, Y. (2015) Molecular pathogenesis of Ehrlichia chaffeensis infection. Annu Rev Microbiol 69: 283304.

Rikihisa, Y. (2017) Subversion of RAB5-regulated autophagy by the intracellular pathogen Ehrlichia chaffeensis. Small GTPases 26: 1-7.

Rivera-Calzada, A., Fronzes, R., Savva, C.G., Chandran, V., Lian, P.W., Laeremans, T., et al. (2013) Structure of a bacterial type IV secretion core complex at subnanometre resolution. EMBO J 32: 11951204.

Robinson, C.G., and Roy, C.R. (2006) Attachment and fusion of endoplasmic reticulum with vacuoles containing Legionella pneumophila. Cell Microbiol 8: 793-805.

Rohrer, S., Holsten, L., Weiss, E., Benghezal, M., Fischer, W., and Haas, R. (2012) Multiple pathways of plasmid DNA transfer in Helicobacter pylori. PLOS ONE 7: e45623.

Rothmeier, E., Pfaffinger, G., Hoffmann, C., Harrison, C.F., Grabmayr, H., Repnik, U., et al. (2013) Activation of Ran GTPase by a Legionella effector promotes microtubule polymerization, pathogen vacuole motility and infection. PLoS Pathog 9: e1003598.

Saadat, I., Higashi, H., Obuse, C., Umeda, M., Murata-Kamiya, N., Saito, Y., et al. (2007) Helicobacter pylori CagA targets PAR1/MARK kinase to disrupt epithelial cell polarity. Nature 447: 330-333. 
Salama, N.R., Hartung, M.L., and Mueller, A. (2013) Life in the human stomach: persistence strategies of the bacterial pathogen Helicobacter pylori. Nat Rev Microbiol 11: 385-399.

Samuels, A.L., Lanka, E., and Davies, J.E. (2000) Conjugative junctions in RP4- mediated mating of Escherichia coli. J Bacteriol 182: 2709-2715.

Savvides, S.N., Yeo, H.J., Beck, M.R., Blaesing, F., Lurz, R., Lanka, E., et al. (2003) VirB11 ATPases are dynamic hexameric assemblies: new insights into bacterial type IV secretion. EMBO J 22: 1969-1980.

Schmidt, T.P., Perna, A.M., Fugmann, T., Böhm, M., Hiss, J., Haller, S., et al. (2016) Identification of Ecadherin signature motifs functioning as cleavage sites for Helicobacter pylori HtrA. Sci Rep 6: 23264.

Schoebel, S., Blankenfeldt, W., Goody, R.S., and Itzen A. (2010) High-affinity binding of phosphatidyllinositol 4-phosphate by Legionella pneumophila DrrA. EMBO Rep 11: 598-604.

Schröder, G., Schuelein, R., Quebatte, M., and Dehio, C. (2011) Conjugative DNA transfer into human cells by the VirB/VirD4 type IV secretion system of the bacterial pathogen Bartonella henselae. Proc Natl Acad Sci USA 108: 14643-14648.

Schulein, R., Guye, P., Rhomberg, T.A., Schmid, M.C., Schröder, G., Vergunst, A.C., et al. (2005) A bipartite signal mediates the transfer of type IV secretion substrates of Bartonella henselae into human cells. Proc Natl Acad Sci USA 102: 856-861.

Segal, G., Feldman, M., and Zusman, T. (2005) The Icm/Dot type-IV secretion systems of Legionella pneumophila and Coxiella burnetii. FEMS Microbiol Rev 29: 65-81.

Selbach, M., Paul, F.E., Brandt, S., Guye, P., Daumke, O., Backert, S., et al. (2009) Host cell interactome of tyrosine-phosphorylated bacterial proteins. Cell Host Microbe 5: 397-403.

Shaffer, C.L., Good J.A., Kumar, S., Krishnan, K.S., Gaddy, J.A., Loh, J.T., et al. (2016) Peptidomimetic small molecules disrupt type IV secretion system activity in diverse bacterial pathogens. MBio 7: e00221-00216.

Sharma, P., Teymournejad, O., and Rikihisa, Y. (2017) Peptide Nucleic Acid knockdown and intra-host cell complementation of Ehrlichia type IV secretion system effector. Front Cell Infect Microbiol. 7: 228. 
Sherwood, R.K., and Roy, C.R. (2016) Autophagy Evasion and Endoplasmic Reticulum Subversion: The Yin and Yang of Legionella Intracellular Infection. Annu Rev Microbiol 70: 413-433.

Siamer, S., and Dehio, C. (2015) New insights into the role of Bartonella effector proteins in pathogenesis. Curr Opin Microbiol 23: 80-85.

Simon, S., Wagner, M.A., Rothmeier, E., Müller-Taubenberger, A., and Hilbi, H. (2014) Icm/Dot-dependent inhibition of phagocyte migration by Legionella is antagonized by a translocated Ran GTPase activator. Cell Microbiol 16: 977-992.

Smeets, L.C., Bijlsma, J.J., Kuipers, E.J., Vandenbroucke-Grauls, C.M., and Kusters, J.G. (2000a) The dprA gene is required for natural transformation of Helicobacter pylori. FEMS Immunol Med Microbiol 27: 99-102.

Smeets, L.C., Bijlsma, J.J., Boomkens, S.Y., Vandenbroucke-Grauls, C.M., and Kusters, J.G. (2000b) comH, a novel gene essential for natural transformation of Helicobacter pylori. J Bacteriol 182: 3948-3954.

Smith, E.P., Miller, C.N., Child, R., Cundiff, J.A., and Celli, J. (2016) Postreplication roles of the Brucella VirB Type IV secretion system uncovered via conditional expression of the VirB11 ATPase. MBio 7: pii: e01730-16.

Sonthayanon, P., Peacock, S.J., Chierakul, W., Wuthiekanun, V., Blacksell, S.D., Holden, M.T., et al. (2010) High rates of homologous recombination in the mite endosymbiont and opportunistic human pathogen Orientia tsutsugamushi. PLoS Negl Trop Dis 4: e752.

Souza, D.P., Oka, G.U., Alvarez-Martinez, C.E., Bisson-Filho, A.W., Dunger, G., Hobeika, L., et al. (2015) Bacterial killing via a type IV secretion system. Nat Commun 6: 6453.

Souza, G., Oka, G., Sgro, L., Coutinho de Oliveira, N., Bueno, W., Cenens, E., et al. (2016) Bacterial Wars: a new role for Type IV Secretion Systems. www.t4ss-conference.de

Starr, T., Ng, T.W., Wehrly, T.D., Knodler, L.A., and Celli, J. (2008) Brucella intracellular replication requires trafficking through the late endosomal/lysosomal compartment. Traffic 9: 678-694. 
Stein, S.C., Faber, E., Bats, S.H., Murillo, T., Speidel, Y., Coombs, N., et al. (2017) Helicobacter pylori modulates host cell responses by CagT4SS-dependent translocation of an intermediate metabolite of LPS inner core heptose biosynthesis. PLoS Pathog 13: e1006514.

Stingl, K., Müller, S., Scheidgen-Kleyboldt, G., Clausen, M., and Maier, B. (2010) Composite system mediates two-step DNA uptake into Helicobacter pylori. Proc Natl Acad Sci USA 107: 1184-1189.

Tegtmeyer, N., Wessler, S., Necchi, V., Rohde, M., Harrer, A., Rau, T.T., et al. (2017a) A unique basolateral type IV secretion model for the CagA oncoprotein of Helicobacter pylori. Cell Host Microbe 22: 552560.e5.

Tegtmeyer, N., Neddermann, M., Asche, C.I., and Backert, S. (2017b) Subversion of host kinases: a key network in cellular signaling hijacked by Helicobacter pylori CagA. Mol Microbiol 105: 358-372.

Toulabi, L., Wu, X., Cheng, Y., and Mao, Y. (2013) Identification and structural characterization of a Legionella phosphoinositide phosphatase. J Biol Chem 288: 24518-24527.

Trokter, M., Felisberto-Rodrigues, C., Christie, P.J., and Waksman, G. (2014) Recent advances in the structural and molecular biology of type IV secretion systems. Curr Opin Struct Biol 27: 16-23.

Urwyler, S. (2009) Proteome analysis of Legionella vacuoles purified by magnetic immunoseparation reveals secretory and endosomal GTPases. Traffic 10: 76-87.

Varga, M.G., Shaffer, C.L., Sierra, J.C., Suarez, G., Piazuelo, M.B., Whitaker, M.E., et al. (2016) Pathogenic Helicobacter pylori strains translocate DNA and activate TLR9 via the cancer-associated cag type IV secretion system. Oncogene 35: 6262-6269.

Vayssier-Taussat, M., Le Rhun, D., Deng, H.K., Biville, F., Cescau, S., Danchin, A., et al. (2010) The Trw type IV secretion system of Bartonella mediates host-specific adhesion to erythrocytes. PLoS Pathog 6: e1000946.

Viala, J., Chaput, C., Boneca, I.G., Cardona, A., Girardin, S.E., Moran, A.P., et al. (2004) Nod1 responds to peptidoglycan delivered by the Helicobacter pylori cag pathogenicity island. Nat Immunol 5: 11661174

Vogel, J.P., and Isberg, R.R. (1999) Cell biology of Legionella pneumophila. Curr Opin Microbiol 2: 30-34. 
Voth, D.E., and Heinzen, R.A. (2007) Lounging in a lysosome: the intracellular lifestyle of Coxiella burnetii. Cell Microbiol 9: 829-840.

Voth, D.E., and Heinzen, R.A. (2009) Coxiella type IV secretion and cellular microbiology. Curr Opin Microbiol 12: 74-80.

Wagner, A., Whitaker, R.J., Krause, D.J., Heilers, J.H., van Wolferen, M., van der Does, C., et al. (2017) Mechanisms of gene flow in archaea. Nat Rev Microbiol 15: 492-501.

Wallden, K., Williams, R., Yan, J., Lian, P.W., Wang, L., Thalassinos, K., et al. (2012) Structure of the VirB4 ATPase, alone and bound to the core complex of a type IV secretion system. Proc Natl Acad Sci U S A 109: 11348-11353.

Wang, Y.A., Yu, X., Silverman, P.M., Harris, R.L., and Egelman, E.H. (2009) The structure of F-pili. J Mol Biol 385: 22-29.

Wang, J., Feng, Y., Wang, C., Srinivas, S., Chen, C., Liao, H., et al. (2017) Pathogenic Streptococcus strains employ novel escape strategy to inhibit bacteriostatic effect mediated by mammalian peptidoglycan recognition protein. Cell Microbiol 19 doi: 10.1111/cmi.12724.

Weber, S., Wagner, M., and Hilbi, H. (2014) Live-cell imaging of phosphoinositide dynamics and membrane architecture during Legionella infection. MBio 5: e00839-13.

Weber, S.S., Ragaz, C., and Hilbi, H. (2009) The inositol polyphosphate 5-phosphatase OCRL1 restricts intracellular growth of Legionella, localizes to the replicative vacuole and binds to the bacterial effector LpnE. Cell Microbiol 11: 442-460.

Weber, S.S., Ragaz, C., Reus, K., Nyfeler, Y., and Hilbi, H. (2006) Legionella pneumophila exploits PI(4)P to anchor secreted effector proteins to the replicative vacuole. PLoS Pathog 2: e46.

Whitaker, N., Chen, Y., Jakubowski, S.J., Sarkar, M.K., Li, F., and Christie, P.J. (2015) The all-alpha domains of coupling proteins from the Agrobacterium tumefaciens VirB/VirD4 and Enterococcus faecalis pCF10-encoded type IV secretion systems confer specificity to binding of cognate DNA substrates. J Bacteriol. 197: 2335-2349. 
Wisniewski, J.A., Traore, D.A., Bannam, T.L., Lyras, D., Whisstock, J.C., and Rood, J.I. (2016) TcpM: a novel relaxase that mediates transfer of large conjugative plasmids from Clostridium perfringens. Mol Microbiol 99: 884-896.

Wisniewski, J.A., and Rood, J.I. (2017) The Tcp conjugation system of Clostridium perfringens. Plasmid 91:28-36.

Wisniewski, J.A., Teng, W.L., Bannam, T.L., and Rood, J.I. (2015) Two novel membrane proteins, TcpD and TcpE, are essential for conjugative transfer of pCW3 in Clostridium perfringens. J Bacteriol 197: 774-781.

Wong, J.J.W., Lu, J., and Glover, J.N.M. (2012) Relaxosome function and conjugation regulation in F-like plasmids - a structural biology perspective. Mol Microbiol 85: 602-617.

Xu, L., Shen, X., Bryan, A., Banga, S., Swanson, M.S., and Luo, Z.Q. (2010) Inhibition of host vacuolar H'ATPase activity by a Legionella pneumophila effector. PLoS Pathog 6: e1000822.

Yeh, Y.C., Lin, T.L., Chang, K.C., and Wang, J.T. (2003) Characterization of a ComE3 homologue essential for DNA transformation in Helicobacter pylori. Infect Immun 71: 5427-5431.

Yeo, H.J., Savvides, S.N., Herr, A.B., Lanka, E., and Waksman, G. (2000) Crystal structure of the hexameric traffic ATPase of the Helicobacter pylori type IV secretion system. Mol Cell 6: 1461-1472.

Yin, S., Li, M., Rao, X., Yao, X., Zhong, Q., Wang, M., et al. (2016) Subtilisin-like protease-1 secreted through type IV secretion system contributes to high virulence of Streptococcus suis 2. Sci Rep 6: 27369.

Zamboni, D.S., McGrath, S., Rabinovitch M., and Roy, C.R. (2003) Coxiella burnetii express type IV secretion system proteins that function similarly to components of the Legionella pneumophila Dot/Icm system. Mol Microbiol 49: 965-976.

Zechner, E.L., Lang, S., and Schildbach, J.F. (2012) Assembly and mechanisms of bacterial type IV secretion machines. Philos Trans R Soc Lond B Biol Sci. 367: 1073-1087. 
Zhang, X.S., Tegtmeyer, N., Traube, L., Jindal, S., Perez-Perez, G., Sticht, H., et al. (2015) A specific A/T polymorphism in Western tyrosine phosphorylation B-motifs regulates Helicobacter pylori CagA epithelial cell interactions. PLoS Pathog 11: e1004621.

Zhao, Y., Liu, G., Li, S., Wang, M., Song, J., Wang, J., et al. (2011) Role of a type IV-like secretion system of Streptococcus suis 2 in the development of streptococcal toxic shock syndrome. J Infect Dis 204: 274-281.

Zimmermann, S., Pfannkuch, L., Al-Zeer, M., Bartfeld, S., Koch, M., Liu, J., et al. (2017) ALPK1 and TIFA dependent innate immune response triggered by the H. pylori type IV secretion system. Cell Rep 20: 2384-2395.

Zweig, M.A., Schork, S., Koerdt, A., Siewering, K., Sternberg, C., Thormann, K., et al. (2013). Secreted single-stranded DNA is involved in the initial phase of biofilm formation by Neisseria gonorrhoeae. Environ Microbiol 3: 1462-2920.

Zusman, T., Yerushalmi, G., and Segal, G. (2003) Functional similarities between the icm/dot pathogenesis systems of Coxiella burnetii and Legionella pneumophila. Infect. Immun 71: 3714-3723.

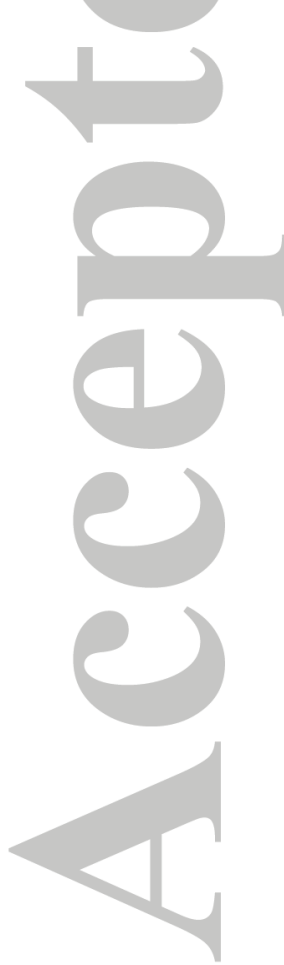




\section{Figure legend}

Figure 1. Schematic representation of type IV secretion architecture and functions in bacteria.

A. Conjugative T4SSs translocate DNA from the donor bacterium into various recipients, including other bacteria or eukaryotic cells.

B. DNA release systems facilitate an exchange of DNA with the extracellular space as well as biofilm formation.

C. DNA uptake from the environment proceeds by the ComB T4SS.

D. The Xanthomonas citri T4SS can deliver a protein toxin to kill neighboring Gram bacterial competitors. E. Various pathogenic bacteria and symbionts have evolved T4SSs to deliver effector proteins or DNAprotein complexes into their host (either eukaryotic target cells or protozoan hosts). The T4SSs can either inject their effectors directly into the host cell or secrete them into the medium, thereby exerting remarkably different effects on host cell functions during infection.

F. EM reconstructions showing the structure of the plasmid R388 T4SS complex and the core complex. Front view (left) and cut-away front view (right) of the T4SS complex (EMD-2567) comprising the core/outer membrane complex (core/OMC, green), the stalk (grey) and the inner membrane complex (IMC, blue). U-tier, M-tier and L-tier stand for upper, middle and lower tier, respectively. The inner (IM) and outer (OM) membranes are indicated.

G. pKM101 core complex (EMD-2232) (top) and truncated core complex lacking the N-terminal part of VirB10 (EMD-2233) (bottom): side view (left) and cut-away side view (right). The bottom right panel shows the superposition of the difference map (between the full-length and the truncated core complex cryo-EM maps) in green, and the cryo-EM structure of the truncated core complex in orange (as in bottom left). The VirB10 N-terminus forms the inner wall of the I-layer and the base.

H. Cryo-EM structure of the TraI relaxase-ssDNA complex revealed the molecular basis of DNA unwinding during bacterial conjugation. 
I. To achieve genetic exchange during bacterial conjugation, two relaxase monomers collaborate, adopting distinct structural conformations to provide the two necessary enzymatic activities for processing the DNA.

J. Individual steps are indicated: (1) TraI opens to bind ssDNA and closes to surround DNA entirely during unwinding. (2) DNA binding to transesterase in closed TraI inhibits nicking. (3) DNA splitting by vestigial helicase. This figure was extensively updated from Backert and Meyer (2006), Trokter et al. (2014) and Ilangovan et al. (2017) with permission from CELL Press.

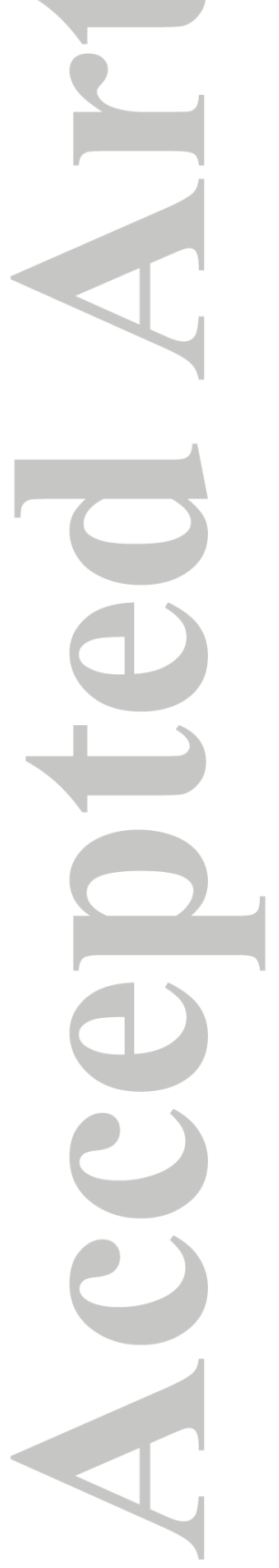


A

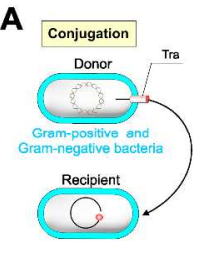

B

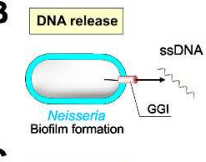

C

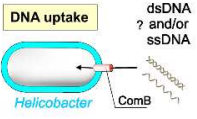

D Toxin delivery Kanthomonas ottri

H

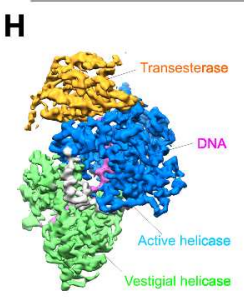

E

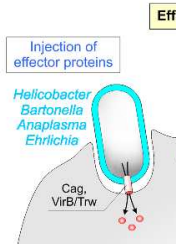

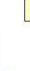

foctor molecule translocation
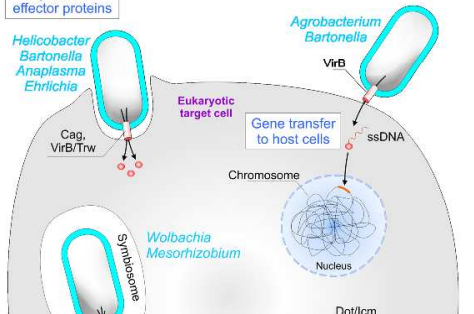

Dotilcm
VirBiTrw

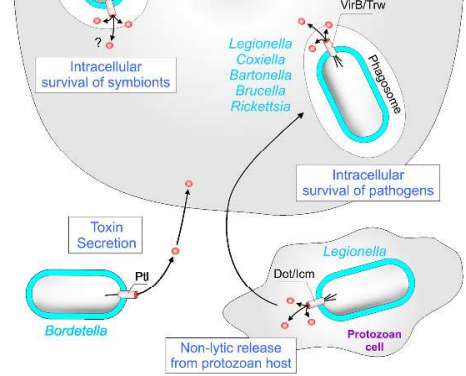

o
$\mathbf{F}$

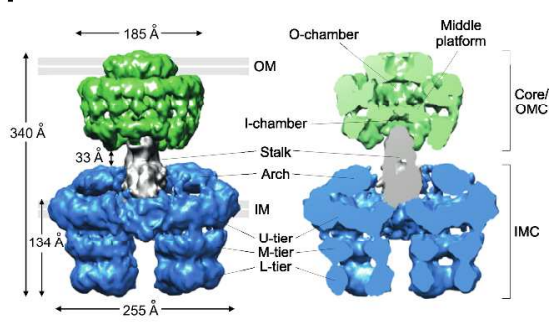

G
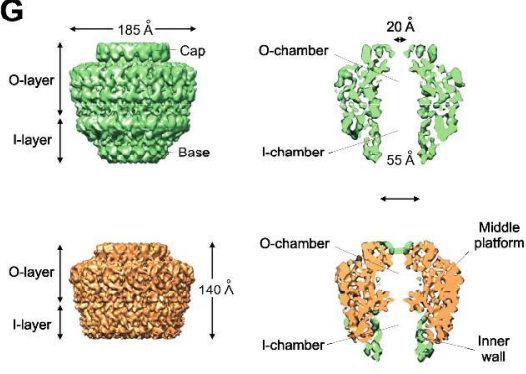

I

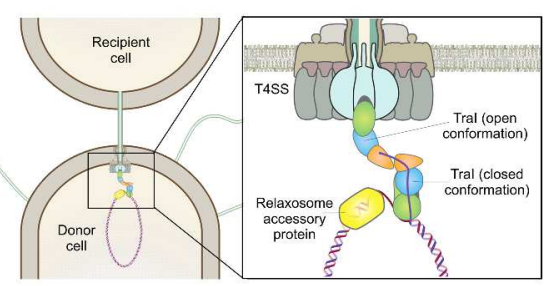

J

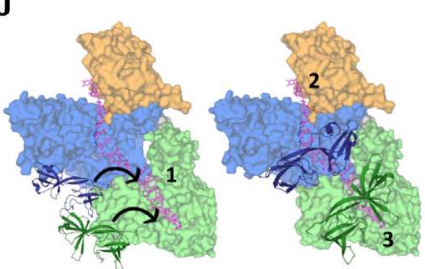

Figure 1. Schematic representation of type IV secretion architecture and functions in bacteria.

A. Conjugative T4SSs translocate DNA from the donor bacterium into various recipients, including other bacteria or eukaryotic cells.

B. DNA release systems facilitate an exchange of DNA with the extracellular space as well as biofilm formation.

C. DNA uptake from the environment proceeds by the ComB T4SS.

D. The Xanthomonas citri T4SS can deliver a protein toxin to kill neighboring Gram- bacterial competitors.

E. Various pathogenic bacteria and symbionts have evolved T4SSs to deliver effector proteins or DNAprotein complexes into their host (either eukaryotic target cells or protozoan hosts). The T4SSs can either inject their effectors directly into the host cell or secrete them into the medium, thereby exerting remarkably different effects on host cell functions during infection.

F. EM reconstructions showing the structure of the plasmid R388 T4SS complex and the core complex. Front view (left) and cut-away front view (right) of the T4SS complex (EMD-2567) comprising the core/outer membrane complex (core/OMC, green), the stalk (grey) and the inner membrane complex (IMC, blue). Utier, M-tier and L-tier stand for upper, middle and lower tier, respectively. The inner (IM) and outer (OM) membranes are indicated.

G. pKM101 core complex (EMD-2232) (top) and truncated core complex lacking the N-terminal part of VirB10 (EMD-2233) (bottom): side view (left) and cut-away side view (right). The bottom right panel shows the superposition of the difference map (between the full-length and the truncated core complex cryo-EM maps) in green, and the cryo-EM structure of the truncated core complex in orange (as in bottom left). The VirB10 N-terminus forms the inner wall of the I-layer and the base.

H. Cryo-EM structure of the TraI relaxase-ssDNA complex revealed the molecular basis of DNA unwinding during bacterial conjugation.

I. To achieve genetic exchange during bacterial conjugation, two relaxase monomers collaborate, adopting distinct structural conformations to provide the two necessary enzymatic activities for processing the DNA. J. Individual steps are indicated: (1) TraI opens to bind sSDNA and closes to surround DNA entirely during 
unwinding. (2) DNA binding to transesterase in closed TraI inhibits nicking. (3) DNA splitting by vestigial helicase. This figure was extensively updated from Backert and Meyer (2006), Trokter et al. (2014) and Ilangovan et al. (2017) with permission from CELL Press.

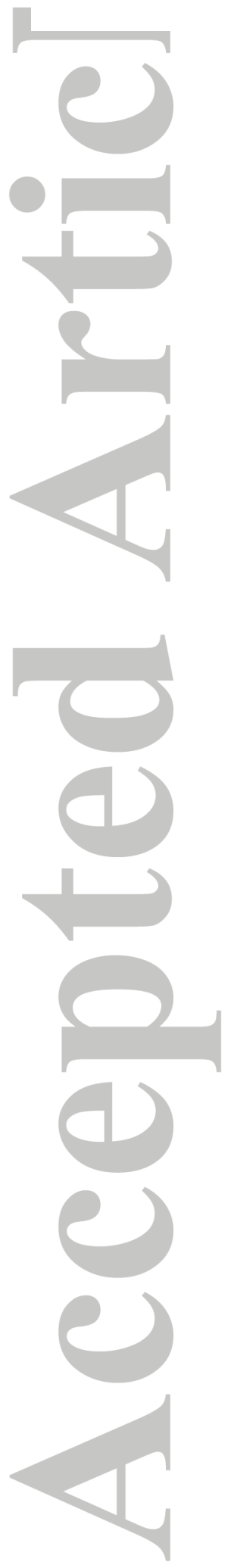

This article is protected by copyright. All rights reserved. 


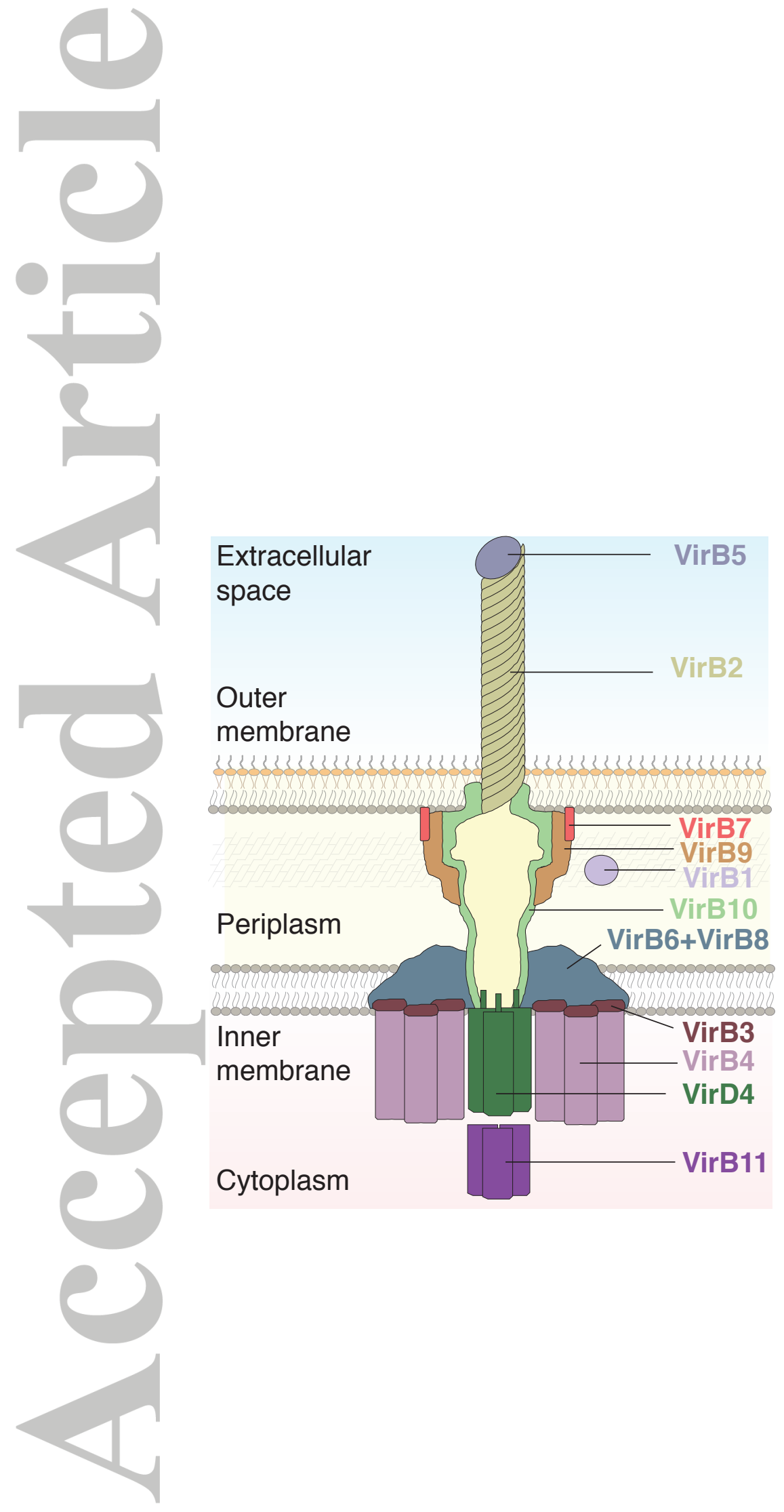




\section{Abbreviated Summary}

Type IV secretion systems (T4SSs) are highly sophisticated nanomachines in the cell envelope of many bacteria. They exhibit crucial roles during infection of humans by the secretion of effector proteins, conjugative transfer of DNA and exchange of DNA with the extracellular environment. In this MicroReview, we summarize recent progress on T4SS composition, assembly and structure, and highlight how basic understanding of their functions is aiding in the design of novel strategies for antimicrobial therapies.
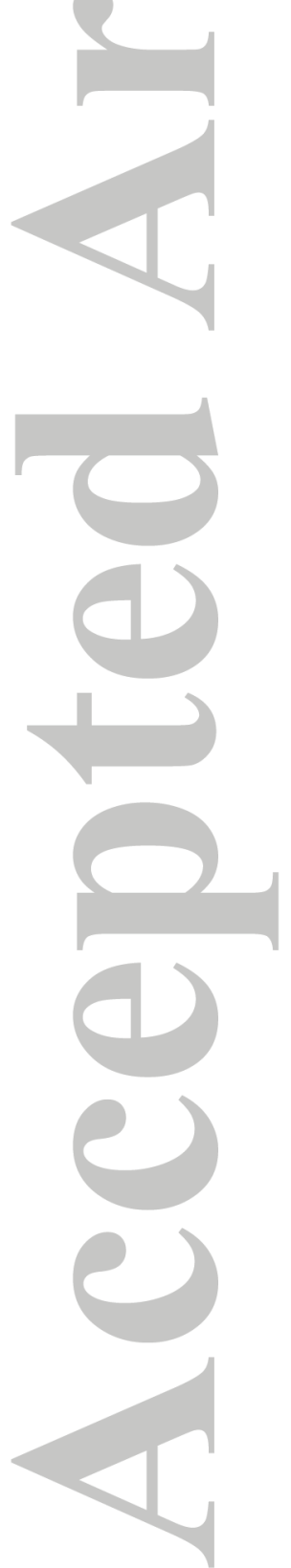